\title{
Fixed Life Projects: Agency conflicts and optimal leverage
}

\author{
Ricardo Correia* ${ }^{\dagger}$ \\ Manchester Business School - University of Manchester \\ Manchester M15 6PB \\ Phone: +44(0)1612756441 \\ Email: RCorreia@dom01.mbs.ac.uk \\ Sydney Howell \\ Manchester Business School - University of Manchester \\ Manchester M15 6PB \\ Email: sydney.howell@mbs.ac.uk \\ Peter Duck \\ Department of Mathematics - University of Manchester \\ Manchester M13 9PL \\ Email: duck@ma.man.ac.uk
}

(preliminary version, comments welcome)

May 2007

* Corresponding author.

$\dagger$ Financial support by Fundação para a Ciência e a Tecnologia (FCT) is gratefully acknowledged. 


\title{
Fixed Life Projects: Agency conflicts and optimal leverage
}

\begin{abstract}
In this paper we analyse a model of the conflicts between equityholders and debtholders regarding the optimal exercise moment for investment in a firm whose only asset is a concession contract. This setting reflects the reality of, not only traditional concessions, but also image rights and audiovisual contracts.

Our results support the coexistence of two different incentives (overinvestment and underinvestment) in one single type of real flexibility (option to invest). We show how overinvestment incentives clearly dominate underinvestment incentives, in terms of their impact in the option value, and show how they tend to occur at or close to maturity of the investment option. We present competing predictions for the size of the agency costs and optimal debt levels, under different market conditions and for different asset characteristics, and reiterate the impact of the agency conflicts in lowering optimal debt levels. Our results also show how different debt repayment schedules optimize the value of the firm operating the concession, even if in some cases the optimal schedule represents the one more sensitive to agency costs.
\end{abstract}




\section{Fixed Life Projects: Agency conflicts and optimal leverage}

\section{Introduction}

This paper analyses the decision to invest in a concession contract where the cost of investment is partially financed by an amortisable commitment loan. It also considers agency conflicts between equityholders and debtholders regarding the timing of investment and assesses the extent to which debt financing and agency conflicts impact the investment decision, in terms of over or underinvestment incentives. Additionally, it analyses the impact of agency conflicts in terms of optimal debt levels and the price of debt.

The study of real options in an agency theory framework is justified by the fact that additional real flexibility (that real options provide by definition) widens the scope of actions an agent may take to pursue his selfish interests. Empirical results widely support this argument (e.g. Bradley, Jarell and Kim, 1984, Long and Malitz, 1985, Smith and Watts, 1992, Barclay, Smith and Watts, 1995 and Mackay, 2003) ${ }^{1}$.

We define a setting where investors have an option to invest in a firm which has as only asset a contract granting it exclusive rights to operate, for a fixed period of time, an asset which continuously releases cash-flows. Investment in this firm represents an irreversible cost which is partially financed with a continuously amortizable commitment $\operatorname{loan}^{2}$. This setting aims at replicating the general characteristics of a concession contract (an oil concession or a public utility concession with the payment of a one time fixed fee) where the concessionaire is entitled to the revenues generated by the business (oil sales, water or energy distribution fees, etc), has exclusive rights over the business (granted by public authority) and has a fixed term for this contract, upon which the asset returns to its owner (there is no residual value for the concessionaire). Other contracts with characteristics that fit these settings are image and audiovisual rights contracts. These contracts have been growing in notoriety especially in sports activities, where nowadays the value of an athletes' image usually represents a significant part of the transfer fees. However, when compared to a classical concession contract, the guarantees of exclusivity in these contracts are weaker due to a void in some countries' legislation protecting the commercial use of a person's image (Penfold et al, 2005, and Veysey, 2002).

\footnotetext{
${ }^{1}$ These studies focus essentially on the impact agency conflicts have in reducing the debt capacity of firms with greater real flexibility.

${ }^{2}$ The use of amortizable debt is a consequence of the fact that these contracts do not have a terminal value. With an amortizable loan there is also a matching of the operational revenues with the financing expenses.
} 
This paper contributes to the literature studying the interactions between investment and financing decisions in the context of time constrained investment decisions. By incorporating agency conflicts it extends on previous work by Mauer and Triantis (1994). It also extends the study of agency conflicts in the context of investment options by considering time constraints, for both the option to delay investment and the subsequent firm, and by embodying to this framework growing investment costs and issuance costs of debt (incorporating in a different environment some of the features of Leland, 1998, Ericsson, 2000 and Mauer and Sarkar, 2005). For all these scenarios it analyses the effect of agency conflicts on the investment decisions and optimal debt levels. The objective is to provide predictions and theoretical arguments regarding the size of agency costs and debt targets in a way that they can be empirically tested. The specific settings of the model prevent generalising most of the conclusions; however this was never the intention. The aim is to study a specific type of contractual relationship which is increasingly more common, and for which there is no thorough analysis in the existing literature.

The structure of the paper is as follows. Section 2 presents the model, beginning with a description of the sequence of decisions and specifying the most important moments. The firms' dynamics are defined first in section 2.1, detailing the differences between the unlevered and the levered firm. Additionally to defining the value of the equity and debt claims this section also defines also the value of the tax shields and bankruptcy costs of debt. Next, section 2.2 defines the two different investment option exercise policies, examining and detailing the differences between them. Additionally to the financial effects of leverage it also defines the effects of the operationally sub-optimal investment decisions. Section 2.3 defines agency costs dividing them between the financial and the purely operational components. Section 3 analyses the results of the numerical simulations in terms of the impact of debt financing and agency conflicts on the investment decision. It examines in detail what happens at the expiry moment of the option to invest. Additionally, it analyses the impact of different market conditions and different asset characteristics on the agency costs of debt and on the optimal debt levels. Finally, section 4 concludes.

\section{The model}

Figure 1 represents the timescale of the model. From $t_{0}$ to $T^{I}$ flexibility represents an option to invest in a firm whose only asset is a concession contract to operate (exploit) $P$ for the period of time $T^{C}$. Considering that investment occurs at $t^{\prime}$, where $t^{\prime}$ represents the stochastic moment in time when the market value of the underlying first reaches the investment 
boundary and $t_{0} \leq t^{\prime} \leq T^{I}$. After investment, from $t^{\prime}$ to $T^{C}+t^{\prime}$ flexibility represents an abandonment option which is exercisable by equity enforcing limited liability. Similarly to $t^{\prime}, t^{\prime}$ ' represents the stochastic moment in time when the market value of the underlying asset first reaches the default boundary.

\section{[INSERT FIGURE 1]}

At $t_{0}$ investors hold an American option to invest in a concession contract with cost $I$ and a commitment loan guarantying, until $T^{I}$, the availability of financing in the amount $F$ with the interest rate $r_{d}$, amortizable during $T^{C}$. The exercise of the investment option creates a firm to operate the concession, beginning operations at $t^{\prime}$ and terminating them at $T^{C}+t^{\prime}$ when the concession expires. Figure 1 illustrates the fact that the moment at which investment occurs is irrelevant for the dynamics and present value of the firm since it does not impact the life expectancy of the firm. Although expiring at different moments, the present value at $t^{\prime}$ is the same ${ }^{3}$.

Like other models incorporating agency conflicts, this model of the equity-debtholder conflict makes two basic assumptions. Firstly, having the capacity to make decisions based on his self interest, the agent (equity, or management acting on behalf of equityholders) will do so. This translates into equityholders basing their investment decisions not on the criteria of firm value maximisation, but on self profit-maximising rationales. Secondly, being aware that the agent has the capacity to act according to his self-interest, the principal (debtholder) anticipates this opportunistic behaviour and prices debt $\left(r_{d}\right)$ based on this assumption ${ }^{4}$. Two different investment option exercise policies ${ }^{5}$ can then be defined. The first-best policy pursues the objective of maximizing the present value of the firm and the second-best policy as pursues the objective of maximizing the present value of equity. In this sense, it represents an approach similar to Mauer and Ott (2000), Titman and Tsyplakov (2002), Childs et al. (2005) and Mauer and Sarkar (2005). Other authors provide a different rational for both policies (e.g. Leland, 1998, Jou and Lee, 2004, Moyen, 2000 or Mao, 2002) ${ }^{6}$.

\footnotetext{
${ }^{3}$ Note that the model represents sequential compound options and not simultaneous, with the exercise of the option to investment the option to abandon operations is created.

${ }^{4}$ The optimal $F$ and the fair interest rate $r_{d}$ are naturally expected to differ for both investment option exercising policies.

${ }^{5}$ Regarding the exercise of the abandonment option there is only one policy, because to formulate a first-best abandonment decision as Leland (1998) points out would lead to a violation of the limited liability rule.

6 The differences are sometimes more of form than substance, in both cases the first-best policy acts as a benchmark and all assume the impossibility of pre-commitment regarding the investment exercise policy, thereby, it is possible to relate the results and conclusions regarding the agency costs. However, in some cases
} 
Section 2.1 defines the dynamics after investment occurs $\left(t>t^{\prime}\right)$. It begins with the unlevered firm $V^{U}(P, t)$ because although the focus is on analysing conflicts between equity and debtholders, the unlevered case is crucial to define the firms' dynamics upon exercise of the abandonment option ${ }^{7}$ and also because $V^{U}(P, t)$ represents the pure operating value of the concession contract. Secondly, the dynamics of the levered firm, equity, debt and debt effects are defined. Section 2.2 focuses on the dynamics prior to the exercise of the option to invest $\left(t<t^{\prime}\right)$. Once again it begins with the unlevered case, which provides the benchmark, which allows determining the operational costs of debt financing. These are defined as overinvestment and underinvestment costs. The two different investment exercise policies, first and second-best are analysed in detail, and the present value for the Net Present Value $(N P V)$ to the levered firm, equity, debt and the present value of the debt effects (financial and operational) is defined. This section concludes with the definition of what constitutes fair rate and optimal leverage. Finally, section 2.3 focuses on the agency costs of debt dividing them into financial and operational costs.

\subsection{Dynamics of the firm}

The underlying asset $P$ represents the present value of the perpetual expected after-tax cash flows that an asset generates. The market value of $P$ follows Geometric Brownian Motion $(\mathrm{gBm})$, evolving according to the following process:

$$
d P=(\mu-\alpha) P d t+\sigma P d z
$$

where $\mu$ represents the total expected market return, $\sigma$ represents volatility and $d z$ is the increment of a standard Wiener process. The cash-flow rate $\alpha$ is assumed to be a constant proportion of $P$, and is paid out to all security holders. Furthermore, it is assumed that financial markets are complete, providing investors with portfolios of traded securities that can replicate the return and risk characteristics of all the assets considered. This allows investors to construct continuously rebalanced self-financing portfolios combining risky and a riskless asset that yields a constant return rate of $r$ per year, replicating the value of the assets.

\subsubsection{The unlevered firm}

(Moyen, 2000, and Mao, 2002) because the authors disregarded the financial impact of the first-best policy it becomes difficult to compare results and conclusions.

${ }^{7} V^{U}$ itself does not have an abandonment option, since there are no fixed costs, no positive abandonment value and $P$ follows $g B m$ (once operating, the value of $V^{U}$ will never be negative). 
$V^{U}(P, t)$ represents an unlevered firm which has acquired a concession to operate (exploit) $P$ during $T^{C}$ and where $t>t^{\prime}$.

Using standard hedging and non-arbitrage arguments $V^{U}(P, t)$ must satisfy the following equation,

$$
\mathrm{L}\left\{V^{U}\right\}+\alpha P=0
$$

With the operator $\mathrm{L}\{X\}$ being equal to the following partial differential equation $(P D E)$,

$$
\mathrm{L}\{X\} \equiv \frac{1}{2} \frac{\partial^{2} X}{\partial P^{2}} \sigma^{2} P^{2}+\frac{\partial X}{\partial t}+(r-\alpha) P \frac{\partial X}{\partial P}-r X
$$

Equation (1) must be solved subject to the following boundary conditions

$$
\begin{aligned}
& V^{U}\left(P, T^{C}+t^{\prime}\right)=0 \\
& V^{U}(0, t)=0
\end{aligned}
$$

Expression (1.a) represents the terminal condition at $T^{C}+t^{\prime}$ when the concession contract expires and operations are terminated. It basically reflects the fact that there is no terminal value for the concession contract. Expression (1.b) represents the absorbing barrier at $P=0$. The closed form solution for $V^{U}(P, t)$ is ${ }^{8}$,

$$
V^{U}(P, t)=\left[1-e^{-\alpha T^{c}}\right] P
$$

The expression of the value of $V^{U}(P, t)$ represents the standard formula for the $N P V$ of an annuity lasting $T^{C}$ of an income stream of $\alpha P$ discounted at the rate $\alpha$. Since there is no possibility of default, the value of the unlevered firm $V^{U}(P, t)$ operating the concession is linear in $P^{9}$. Notice also that the value of $V^{U}(P, t)$ is the same regardless of the moment in time when investment occurs. It represents only a function of the market value of the underlying asset, the rate at which it releases cash-flows and the tenure of the concession contract.

\subsubsection{The levered firm}

Since there is no terminal value when the contract expires, for a concessionaire the only source of income are the cash flows the asset generates during the life of the contract. It is

\footnotetext{
${ }^{8}$ The derivation of the PDE and the analytical solution of $V^{U}(P, t)$ are presented in Appendix I.

${ }^{9}$ This solution also fits the Capital Asset Pricing Model for a dividend-paying asset $P$, since if $P$ pays $\alpha$ on its market value, the capitalization factor of $\alpha$ can be used to value the perpetuity of annual payments $\alpha P$, giving the correct value $\alpha P / \alpha=P$.
} 
then important to analyse the cash flows accruing to the different stakeholders of the firm when the investment is partially financed with debt.

The use of debt financing is justified by the fact that interest payments contrary to dividends are tax deductible. In this model taxes are represented by a corporate tax rate $\tau$ and a symmetrical tax system allowing for full loss offset provisions ${ }^{10}$. Debt is represented by a commitment loan; namely a contractual promise signed at $t_{0}$ to lend an amount $F$ at a predetermined rate $r_{d}$ for a period of time $T^{C}$, during which the firm will regularly make interest and amortization payments.

At the moment debt is issued the firm will incur issuance costs of $\kappa F$. Since there is no terminal value at expiry of the concession contract, debt is amortized during the life of the concession. Two different scenarios regarding the debt repayment schedule are considered: a constant repayments schedule - increasing amortizations, and a constant amortizations schedule - decreasing debt service payments ${ }^{11}$.

The differences between equityholders and debtholders objectives concern the moment when investment occurs. After investment occurs, the impact of the different investment option exercise polices results in different amounts of debt $F$ and in a different fair rate $r_{d}$. However, the dynamics of the levered firm under the different investment option exercise policies are similar. Thereby, for the sake of simplicity, throughout the analysis of the levered firm the superscript $\Phi \in\{F, S\}$ is used, where $F$ stands for the first-best and $S$ stands for the second-best exercise policy. The use of the superscript $\Phi$ reminds constantly that although the firms' dynamics are similar, there are differences in the amounts and price of debt for the two investment polices considered.

The cash flows accruing to debt $D^{\Phi}\left(P, F^{\Phi}, r_{d}^{\Phi}, t\right)$, are $c^{\Phi}\left(F^{\Phi}, r_{d}^{\Phi}, t, T^{C}\right)$ comprehending interests and amortization. The interest tax shields of debt are defined by $s^{\Phi}\left(F^{\Phi}, r_{d}^{\Phi}, t, T^{C}\right)$ and they merely comprehend the tax savings on the instantaneous interest payments because amortization payments are not tax deductible. The cash flows accruing to the levered firm $V^{\Phi}\left(P, F^{\Phi}, r_{d}^{\Phi}, t\right)$ are $\alpha P+s^{\Phi}\left(F^{\Phi}, r_{d}^{\Phi}, t, T^{C}\right)$, including the operational cash flows plus the interest tax shields of debt. Equity $E^{\Phi}\left(P, F^{\Phi}, r_{d}^{\Phi}, t\right)$, is entitled to the difference between the cash flows the levered firm generates (operational and tax shields) and the cash flows

\footnotetext{
${ }^{10}$ The model could be easily adapted to accommodate a partially symmetrical or asymmetrical tax system and also personal taxation of coupons, dividends or capital gains.

${ }^{11}$ Appendix 2 presents the derivation of the cash flows accruing to debt and the interest tax shields of debt for both amortization schedules.
} 
accruing to debt, $\alpha P+s^{\Phi}\left(F^{\Phi}, r_{d}^{\Phi}, t, T^{C}\right)-c^{\Phi}\left(F^{\Phi}, r_{d}^{\Phi}, t, T^{C}\right)$. When this difference is positive, it will be paid out as a dividend, whenever it is negative, equity will make cash injection in the form of a shareholders' loan (pseudo equity without commitment to receive interests). These payments will always be made until their value becomes larger than the present value of the future expected cash flows to equity, upon which equity defaults on the debt payments surrendering the firm to debtholders. Table 1 summarizes all the assets valued at a firm level and at an option level.

\section{[INSERT TABLE1]}

Again, using standard hedging and non-arbitrage arguments we derived the equation that governs the value of $E^{\Phi}\left(P, F^{\Phi}, r_{d}^{\Phi}, t\right)$,

$$
\mathrm{L}\left\{E^{\Phi}\right\}+\alpha P+s^{\Phi}-c^{\Phi}=0
$$

The value of equity must satisfy the following boundary conditions, where $P_{D}$, represents the value of $P$ at which equity optimally chooses to default at moment $t^{12}$,

$$
\begin{aligned}
& E^{\Phi}\left(P, F^{\Phi}, r_{d}^{\Phi}, T^{C}+t^{\prime}\right)=0 \\
& E^{\Phi}\left(P_{D}, F^{\Phi}, r_{d}^{\Phi}, t\right)=0 \\
& \left.\frac{\partial E^{\Phi}}{\partial P}\right|_{P=P_{D}}=0
\end{aligned}
$$

Boundary (2.a) reflects the fact that there is no residual value when the concession contract expires. Boundary (2.b) enforces the limited liability and absolute priority rules, ensuring that equity remains a residual claimant with limited liability. In option terms the option to abandon represents a put option on the shares that equity holds with a strike price of zero. Boundary (2.c) represents the smooth pasting condition and ensures that the decision of equity to default on debt payments and surrender the firm to debtholders is optimally $\operatorname{chosen}^{13}$.

The value of the levered firm $V^{\Phi}\left(P, F^{\Phi}, r_{d}^{\Phi}, t\right)$ is governed by,

$$
\mathrm{L}\left\{V^{\Phi}\right\}+\alpha P+s^{\Phi}=0
$$

\footnotetext{
${ }^{12} P_{D}(t)$ represents the default boundary throughout the life of the concession, some authors choose to refer to it as the default trigger function.

${ }^{13}$ Although we present the smooth pasting conditions for exercise of the abandonment and investment options, they were not explicitly used in the solution of the model, since its complexity precluded any analytical solution. The numerical solution adopted however, insured the optimality of the decisions to abandon or invest in both policies considered.
} 
The value of the firm must satisfy the following boundary conditions,

$$
\begin{aligned}
& V^{\Phi}\left(P, F^{\Phi}, r_{d}^{\Phi}, T^{C}+t^{\prime}\right)=0 \\
& V^{\Phi}\left(P_{D}, F^{\Phi}, r_{d}^{\Phi}, t\right)=V^{U}\left(P_{D}, t\right)(1-\delta)=P_{D}\left[1-e^{-\alpha\left(T^{C}+t^{\prime}-t\right)}\right](1-\delta)
\end{aligned}
$$

Boundary (3.a) reflects the fact that at maturity there is no liquidation value for the firm. Boundary (3.b) represents the value matching condition when equity optimally decides to default on the debt payments. Since debtholders become the owners of the firm, the firm becomes unlevered and additionally depreciates $\delta$ representing the bankruptcy costs of debt. The value of debt $D^{\Phi}\left(P, F^{\Phi}, r_{d}^{\Phi}, t\right)$ satisfies the following equation,

$$
\mathrm{L}\left\{D^{\Phi}\right\}+c^{\Phi}=0
$$

With the following boundary conditions,

$$
\begin{aligned}
& D^{\Phi}\left(P, F^{\Phi}, r_{d}^{\Phi}, T^{C}+t^{\prime}\right)=0 \\
& D^{\Phi}\left(P_{D}, F^{\Phi}, r_{d}^{\Phi}, t\right)=V^{\Phi}\left(P_{D}, F^{\Phi}, r_{d}^{\Phi}, t\right)=P_{D}\left[1-e^{-\alpha\left(T^{C}+t^{\prime}-t\right)}\right](1-\delta)
\end{aligned}
$$

Boundary (4.a) reflects the fact that at expiry of the concession contract debt is fully amortised. Boundary (4.b) represents the value matching condition at default. Debt becomes the sole owner of an unlevered firm, which deprecated in the proportion $\delta$.

The impact of debt financing can be decomposed in two effects, interest tax shields of debt and bankruptcy costs of debt. Tax shields $S^{\Phi}\left(P, F^{\Phi}, r_{d}^{\Phi}, t\right)$ represent a claim held by all the stakeholders of the firm on a 'subsidy' given by government in the form of tax savings. Bankruptcy costs $B(P, t)$ represent a claim on the firms' assets (in the form of administrative and legal costs) held by auditors, lawyers, etc. Their value is driven by the following equations,

$$
\begin{aligned}
& \mathrm{L}\left\{S^{\Phi}\right\}+s^{\Phi}=0 \\
& \mathrm{~L}\left\{B^{\Phi}\right\}=0
\end{aligned}
$$

At expiry of the concession contract the terminal conditions are,

$$
\begin{aligned}
& S^{\Phi}\left(P, F^{\Phi}, r_{d}^{\Phi}, T^{C}+t^{\prime}\right)=0 \\
& B\left(P, T^{C}+t^{\prime}\right)=0
\end{aligned}
$$

At expiry of the concession contract the firm is liquidated, debt is fully amortized, there are no more interest tax shields of debt and no bankruptcy costs. 
When equity optimally decides to default on the debt payments, the following value matching boundaries apply for $S^{\Phi}\left(P_{D}, F^{\Phi}, r_{d}^{\Phi}, t\right)$ and $B\left(P_{D}, t\right)$,

$$
\begin{aligned}
& S^{\Phi}\left(P_{D}, F^{\Phi}, r_{d}^{\Phi}, t\right)=0 \\
& B\left(P_{D}, t\right)=P_{D}\left[1-e^{-\alpha\left(T^{C}+t^{\prime}-t\right)}\right] \delta
\end{aligned}
$$

At default, debtholders become the sole owners of an unlevered firm. There are no more interest payments and no more tax shields of debt being generated, from that moment on debtholders become equityholders and whatever cash flows they receive are dividends. Bankruptcy costs represent the portion of the unlevered firm value that is lost during the bankruptcy procedures.

\subsection{Dynamics of the investment option}

Investors can acquire the concession by paying $I$ growing at a constant rate of $\gamma$. This cost will be partially financed with the proceedings from the commitment loan.

The unlevered case, once again, provides the benchmark against which the impact of debt financing becomes obvious. It is also important to determine the costs of the operationally suboptimal investment exercise policies.

$V_{0}^{U}(P, t)$ represents an American call option on the assets $V^{U}(P, t)$, with a strike price of $I e^{\gamma t}$.and where $t<t^{\prime}$. Its value must satisfy,

$$
\mathrm{L}\left\{V_{0}^{U}\right\}=0
$$

with the following boundary conditions, where $P_{I}$ represents the asset value at which investors will optimally exercise the option to invest in the unlevered firm at moment $t$,

$$
\begin{aligned}
& V_{0}^{U}\left(P, T^{I}\right)=\max \left[V^{U}\left(P, T^{I}\right)-I e^{\gamma T^{I}}, 0\right]=\max \left[P\left(1-e^{-\alpha T^{C}}\right)-I e^{\gamma T^{I}}, 0\right] \\
& V_{0}^{U}\left(P_{I}, t\right)=V^{U}\left(P_{I}, t\right)-I e^{\gamma t}=P_{I}\left(1-e^{-\alpha T^{C}}\right)-I e^{\gamma t} \\
& \left.\frac{\partial V_{0}^{U}}{\partial P}\right|_{P=P_{I}}=\left.\frac{\partial V^{U}}{\partial P}\right|_{P=P_{I}}
\end{aligned}
$$

Boundary (7.a) reflects the comparison between the $N P V$ for investment at expiry of the investment option with the value of letting the option expire unexercised. At expiry investment optimally occurs for positive $N P V$ values. Condition (7.b) represents the 
investment option free exercise boundary. Condition (7.c) insures that the asset value at which investment occurs is the one that maximizes the value of $V_{0}^{U}$.

\subsubsection{First-best investment option exercise policy}

Similarly to the analysis of the unlevered case, the first-best policy is also important as a benchmark. Would it be possible to pre-commit to an optimal exercise policy at firm level, and all actors (the various stakeholders of the firm) would be better off. However, it is unrealistic to consider that such covenants could either be written in a debt contract or enforced without incurring in prohibitively high monitoring costs. The analysis of the differences between the first-best case and the second-best case provide the expected size of the opportunity cost, which is incurred by society at large and shareholders in particular, for not having a better contractual system. $V_{0}^{F}(P, t)$ represents the value of the option to invest on $V^{F}\left(P, F^{F}, r_{d}^{F}, t\right)$. In simple terms it represents an American call option on the assets $V^{F}\left(P, F^{F}, r_{d}^{F}, t\right)$, with a strike price of $I e^{\gamma t}$. The best definition for $V_{0}^{F}\left(P, t_{0}\right)$ is the present value of the $N P V$ to a levered firm that follows an investment exercise policy of $N P V$ to levered firm maximization. Its value must satisfy,

$$
\mathrm{L}\left\{V_{0}^{F}\right\}=0
$$

$V_{0}^{F}(P, t)$ must also satisfy the following boundary conditions, where $P_{I}^{F}$ represents the asset value at which investors optimally exercise the option to invest in the unlevered firm at $t$,

$$
\begin{aligned}
& V_{0}^{F}\left(P, T^{I}\right)=\max \left[V^{F}\left(P, F^{F}, r_{d}^{F}, t^{I}\right)-I e^{\gamma T^{I}}-\kappa F^{F}, 0\right] \\
& V_{0}^{F}\left(P_{I}^{F}, t\right)=V^{F}\left(P_{I}^{F}, F^{F}, r_{d}^{F}, t\right)-I e^{\gamma t}-\kappa F^{F} \\
& \left.\frac{\partial V_{0}^{F}}{\partial P}\right|_{P=P_{I}^{F}}=\left.\frac{\partial V^{F}}{\partial P}\right|_{P=P_{I}^{F}}
\end{aligned}
$$

Boundary (8.a) represents an expression of the $N P V$ of the investment to the levered firm. It compares the expected present value of $V^{F}\left(P, F^{F}, r_{d}^{F}, t\right)$ with the investment cost, including the costs of issuing debt $\kappa F^{F}$. As expected, at expiry, investment optimally occurs for positive $N P V$ values. Note that this is no longer a purely operational $N P V$, since $V^{F}\left(P, F^{F}, r_{d}^{F}, t\right)$ includes the present value of interest tax shields and bankruptcy costs of 
debt. Boundary (8.b) represents the value matching at exercise of the investment option prior to expiry and condition (8.c) insures that $P_{I}^{F}$ is chosen to maximize the value of $V_{0}^{F}$.

\subsubsection{Second-best investment option exercise policy}

Being able to decide when to invest, equityholders naturally favour maximizing their own wealth in detriment of maximizing the combined wealth of all the stakeholders of the firm. $E_{0}^{S}(P, t)$ represents the present value of the $N P V$ to equity in a firm that follows an investment exercise policy of $N P V$ to equity maximization. The equation governing its value is $^{14}$,

$$
\mathrm{L}\left\{E_{0}^{S}\right\}=0
$$

The value of $E_{0}^{S}\left(P, t^{I}\right)$ must satisfy the following boundary conditions, where $P_{I}^{S}$ represents the asset value, at which investment occurs in the second-best investment option policy,

$$
\begin{aligned}
& E_{0}^{S}\left(P, T^{I}\right)=\max \left[E^{S}\left(P, F^{S}, r_{d}^{S}, T^{I}\right)-\left(I e^{\gamma T^{I}}-F^{S}\right)-\kappa F^{S}, 0\right] \\
& E_{0}^{S}\left(P_{I}^{S}, t^{I}\right)=E^{S}\left(P_{I}^{S}, F^{S}, r_{d}^{S}, t^{I}\right)-\left(I e^{\gamma t^{I}}-F^{S}\right)-\kappa F^{S} \\
& \left.\frac{\partial E_{0}^{S}}{\partial P}\right|_{P=P_{I}^{S}}=\left.\frac{\partial E^{S}}{\partial P}\right|_{P=P_{I}^{S}}
\end{aligned}
$$

Boundary (9.a) reflects the second-best investment exercise policy at maturity of the investment option. This policy aims at maximizing the $N P V$ to equity, rather than the $N P V$ to firm. It can occur that under the second-best policy equityholders optimally exercise the investment option at negative values of the $N P V$ to the levered firm ${ }^{15}$. Boundary condition (9.b) represents the free boundary at investment option exercise. Condition (9.c) insures that $P_{I}^{S}$ is chosen to maximize the value of $E_{0}^{S}{ }^{16}$. Conditions (9.a) and (9.b) disregard the possibility of all-equity finance because of the adverse consequences of keeping this

\footnotetext{
${ }^{14}$ Equation (8) also governs the value of $V_{0}^{S}(P, t)$ and similarly does equation (9) for the value of $E_{0}^{F}(P, t)$.

${ }^{15}$ The value matching condition at maturity of the investment option considering the second-best policy for $V_{0}^{S}\left(P_{I}^{S}, T^{I}\right)$ is $V_{0}^{S}\left(P_{I}^{S}, T^{I}\right)=V^{S}\left(P_{I}^{S}, F^{S}, r_{d}^{S}, T^{I}\right)-I e^{\gamma T^{I}}-\kappa F^{S}$. Similarly for equity in the first-best policy, the value matching condition at exercise of the investment option is $E_{0}^{F}\left(P_{I}^{F}, T^{I}\right)=E^{F}\left(P_{I}^{F}, F^{F}, r_{d}^{F}, T^{I}\right)-I e^{\gamma T^{I}}+F^{F}-\kappa F^{F}$. ${ }^{16}$ The value matching condition for $V_{0}^{S}\left(P_{I}^{S}, t\right)$ is $V_{0}^{S}\left(P_{I}^{S}, t\right)=V^{S}\left(P_{I}^{S}, F^{S}, r_{d}^{S}, t\right)-I e^{\gamma t}-\kappa F^{S}$. For equity, in the first-best exercise policy the value matching condition is $E_{0}^{F}\left(P_{I}^{F}, t\right)=E^{F}\left(P_{I}^{F}, F^{F}, r_{d}^{F}, t\right)-\left(I e^{\gamma t}-F^{F}\right)-\kappa F^{F}$.
} 
possibility open. By including a negative covenant preventing the firm to issue any new securities, equityholders can, and gladly pre-commit themselves not to do so $^{17}$.

The relationship and differences between both investment exercise policies, become clear in the analysis of the terminal boundaries at expiry of the investment option.

Boundary condition (8.a) can also be expressed as,

$$
V_{0}^{F}\left(P, T^{I}\right)=\max \left[E^{F}\left(P, F^{F}, r_{d}^{F}, T^{I}\right)-\left(I e^{\gamma T^{I}}-F^{F}-\kappa F^{F}\right)+D^{F}\left(P, F^{F}, r_{d}^{F}, T^{I}\right)-F^{F}, 0\right]
$$

This expression basically states that the $N P V$ to the levered firm equals the sum of the $N P V$ to equity and the $N P V$ to debt.

Considering that the decision to invest is made by the equityholders ${ }^{18}$, for investment to occur at expiry of the option to invest it is sufficient that $E^{S}\left(P, F^{S}, r_{d}^{S}, T^{I}\right)-\left(I e^{\gamma T^{I}}-F^{S}-\kappa F^{S}\right)$

is greater than zero. Thereby the investment rule for the second-best policy becomes,

$$
E_{0}^{S}\left(P, T^{I}\right)=\max \left[E^{S}\left(P, F^{S}, r_{d}^{S}, T^{I}\right)-\left(I e^{\gamma T^{I}}-F^{S}-\kappa F^{S}\right), 0\right]
$$

By replacing $E^{S}\left(P, F^{S}, r_{d}^{S}, T^{I}\right)=V^{S}\left(P, F^{S}, r_{d}^{S}, T^{I}\right)-D^{S}\left(P, F^{S}, r_{d}^{S}, T^{I}\right)$, the differences between both policies become clear. In the second best policy investment occurs, when,

$$
V^{S}\left(P, F^{S}, r_{d}^{S}, T^{I}\right)-D^{S}\left(P, F^{S}, r_{d}^{S}, T^{I}\right)-\left(I e^{\gamma T^{I}}-F^{S}-\kappa F^{S}\right)>0 .
$$

This can be expressed as,

$$
V^{S}\left(P, F^{S}, r_{d}^{S}, T^{I}\right)-\left(I e^{\gamma T^{I}}-\kappa F^{S}\right)>D^{S}\left(P, F^{S}, r_{d}^{S}, T^{I}\right)-F^{S}
$$

The left hand side of the inequality represents the first-best policy investment valuematching condition ( $N P V$ to firm). The right hand side represents the $N P V$ to debt, or more commonly the difference between the market value of debt and its face value.

As long as the market value of debt equals its face value, there is no difference between the first and the second-best policies and the second-best investment rule collapses to the firstbest. However, in a commitment loan, only by chance will the face value of debt equal its market value at any moment $t$ for, $t_{0} \leq t \leq T^{I}$. Whenever, the market value of debt is lower than its face value, there will always be a degree of overinvestment of the second-best policy relatively to the first-best. Rational equityholders invest at lower values of the underlying asset $\left(P_{I}^{S}\left(T^{I}\right)<P_{I}^{F}\left(T^{I}\right)\right)$ and finance the negative $N P V$ to firm with the wealth they are free

\footnotetext{
${ }^{17}$ By keeping the possibility of pursuing investments solely financed with debt, equityholders would explicitly deprive debtholders of any upside potential, forcing them to raise the credit spread and lowering the debt capacity of the firm. The consequences for equity of such high credit spreads would in most cases completely eliminate the positive effects of debt financing. Thereby being able to do so, equityholders are willing to precommit to, when investing doing so using the proceeds of the commitment loan. We have modelled this possibility and it virtually eliminates any positive aspects of debt financing.

${ }^{18}$ Or by the managers on behalf of the equityholders, with the objective of maximizing $E_{0}^{S}(P, t)$
} 
to expropriate from debtholders. As long as the $N P V$ to debt is lower than the $N P V$ to firm, equityholders are always willing to invest. The opposite will never occur. The $N P V$ to debtholders will never be greater than the $N P V$ to the firm, given the fact that debt does not have the upside potential of favourable movements in $P$.

\subsubsection{Net present value to debt and debt effects at the level of the investment option}

$D_{0}^{\Phi}(P, t)^{19}$ represents the present value of the $N P V$ to debt. Its value is a function of $D^{\Phi}\left(P, F^{\Phi}, r_{d}^{\Phi}, t\right)$ but also of $P_{I}^{\Phi}(t)$ the investment boundary. The value of $D_{0}^{\Phi}(P, t)$ must satisfy,

$$
\mathrm{L}\left\{D_{0}^{\Phi}\right\}=0
$$

The value of $D_{0}^{\Phi}(P, t)$ must respect the following boundary conditions,

$$
\begin{aligned}
& D_{0}^{\Phi}\left(P_{I}^{\Phi}, T^{I}\right)=D^{\Phi}\left(P_{I}^{\Phi}, F^{\Phi}, r_{d}^{\Phi}, T^{I}\right)-F^{\Phi} \\
& D_{0}^{\Phi}\left(P_{I}^{\Phi}, t\right)=D^{\Phi}\left(P_{I}^{\Phi}, F^{\Phi}, r_{d}^{\Phi}, t\right)-F^{\Phi}
\end{aligned}
$$

At maturity of the investment option, boundary (10.a), represents the value-matching condition at exercise of the investment option. Similarly to boundary conditions (8.a) and (9.a) it also represents an $N P V$ formulation, in this case the $N P V$ to debt. The difference between the market value of debt at the exercise moment of the investment option $D^{\Phi}\left(P, F^{\Phi}, r_{d}^{\Phi}, T^{I}\right)$ and the cost of investment to debt $F^{\Phi}$. Prior to expiry of the investment option, boundary (10.b), represents the value-matching condition along the investment boundary $P_{I}^{\Phi}(t)$.

The value of the interest tax shields $S^{\Phi}\left(P, F^{\Phi}, r_{d}^{\Phi}, t\right)$ and bankruptcy costs $B(P, t)$ prior to investment occurs are represented by $S_{0}^{\Phi}(P, t)$ and $B_{0}^{\Phi}(P, t)$.

One more effect is taken into account, the issuance costs of debt $K_{0}^{\Phi}(P, t) \cdot K_{0}^{\Phi}(P, t)$ represents the present value of the issuance costs as a function of time and amount of leverage. They represent an additional cost of investment in the levered firm relatively to the

\footnotetext{
${ }^{19}$ For the assets we now analyse, the impact of the two different investment option exercise policies is in defining the exercise free boundary $P_{I}^{F}(t)$ for the first-best policy and $P_{I}^{S}(t)$ for the second-best policy. The dynamics of the assets we define henceforth are similar for both policies, thereby, we will use the superscript $\Phi$ once again, in order to avoid redundancy.
} 
unlevered firm. When investment occurs in the levered case two options are being exercised, the option to invest in a levered firm and the option to take in debt.

The value of $S_{0}^{\Phi}(P, t), B_{0}^{\Phi}(P, t)$ and $K_{0}^{\Phi}(P, t)$ must satisfy,

$$
\begin{aligned}
& \mathrm{L}\left\{S_{0}^{\Phi}\right\}=0 \\
& \mathrm{~L}\left\{B_{0}^{\Phi}\right\}=0 \\
& \mathrm{~L}\left\{K_{0}^{\Phi}\right\}=0
\end{aligned}
$$

$S_{0}^{\Phi}(P, t), B_{0}^{\Phi}(P, t)$ and $K_{0}^{\Phi}(P, t)$ must satisfy the following boundary conditions, where $P_{I}^{\Phi}(t)$ represents the investment boundary,

$$
\begin{aligned}
& S_{0}^{\Phi}\left(P_{I}^{\Phi}, T^{I}\right)=S^{\Phi}\left(P_{I}^{\Phi}, F^{\Phi}, r_{d}^{\Phi}, T^{I}\right) \\
& B_{0}^{\Phi}\left(P_{I}^{\Phi}, T^{I}\right)=B\left(P_{I}^{\Phi}, T^{I}\right) \\
& K_{0}^{\Phi}\left(P_{I}^{\Phi}, T^{I}\right)=\kappa F^{\Phi}
\end{aligned}
$$

Boundaries (11.a), (12.a) and (13.a) represent the terminal boundaries at expiry of the investment option when investment occurs. Their value is zero otherwise.

$$
\begin{aligned}
& S_{0}^{\Phi}\left(P_{I}^{\Phi}, t\right)=S^{\Phi}\left(P_{I}^{\Phi}, F^{\Phi}, r_{d}^{\Phi}, t\right) \\
& B_{0}^{\Phi}\left(P_{I}^{\Phi}, t\right)=B\left(P_{I}^{\Phi}, t\right) \\
& K_{0}^{\Phi}\left(P_{I}^{\Phi}, t\right)=\kappa F^{\Phi}
\end{aligned}
$$

Prior to expiry of the investment option, boundaries (11.b), (12.b) and (13.b) represent the investment value matching conditions.

\subsubsection{Over and underinvestment costs}

So far the effects of debt financing impacted either the value of the firm or the cost of investment $\left(K_{0}^{\Phi}(P, t)\right.$ indirectly increases the cost of investing). In reality, the differences between the investment boundaries also represent effects of debt financing. To account for these costs two effects are defined, overinvestment $O_{0}^{\Phi}(P, t)$ and underinvestment $U_{0}^{\Phi}(P, t)$ costs. These effects are always negative or zero, because they reflect a deviation from an operationally optimal exercise decision. Overall, the changes in the investment boundary are positive for the firm because it allows it to increase the amount of interest tax shields. 
However, it incorporates costs; a direct cost from issuing debt in terms of increased bankruptcy costs and issuance costs, and indirect costs in terms of the operational suboptimalitity of the exercise policy.

The values of $O_{0}^{\Phi}(P, t)$ and $U_{0}^{\Phi}(P, t)$ are described by,

$$
\begin{aligned}
& \mathrm{L}\left\{O_{0}^{\Phi}\right\}=0 \\
& \mathrm{~L}\left\{U_{0}^{\Phi}\right\}=0
\end{aligned}
$$

They must satisfy the following terminal and free boundary conditions,

When $P_{I}^{\Phi}\left(T^{I}\right)<P_{I}\left(T^{I}\right)$, for $P_{I}^{\Phi}\left(T^{I}\right)<P\left(T^{I}\right)<P_{I}\left(T^{I}\right)$

$$
O_{0}^{\Phi}\left(P_{I}^{\Phi}, T^{I}\right)=I e^{\gamma T^{I}}-V^{U}\left(P_{I}^{\Phi}, T^{I}\right)
$$

When $P_{I}^{\Phi}\left(T^{I}\right)>P_{I}\left(T^{I}\right)$, for $P_{I}\left(T^{I}\right)<P\left(T^{I}\right)<P_{I}^{\Phi}\left(T^{I}\right)$

$$
U_{0}^{\Phi}\left(P_{I}^{\Phi}, T^{I}\right)=V^{U}\left(P_{I}^{\Phi}, T^{I}\right)-I e^{\gamma T^{I}}
$$

Condition (14.a) represents the terminal boundary condition at expiry of the investment option for the overinvestment effect. Overinvestment occurs when it is optimal to invest in the levered, but not in the unlevered firm. Although being optimal to invest in the levered firm, investment occurs at negative operational $N P V$ values $O_{0}^{\Phi}\left(P, T^{I}\right)$ represents then this negative $N P V$. The alternative situation is represented by (15.a) when it is not optimal to invest in the levered firm but it is in the unlevered firm. Underinvestment costs, represent in this case the positive operational $N P V$ values forgone due to the existence of debt financing ${ }^{20}$.

When $P_{I}^{\Phi}(t)<P_{I}(t)$, for $P_{I}^{\Phi}(t)<P(t)<P_{I}(t)$

$$
O_{0}^{\Phi}\left(P_{I}^{\Phi}, t\right)=V_{0}^{U}\left(P_{I}^{\Phi}, t\right)-\left(V^{U}\left(P_{I}^{\Phi}, t\right)-I e^{\gamma t}\right)
$$

When $P_{I}^{\Phi}(t)>P_{I}(t)$, for $P_{I}(t)<P(t)<P_{I}^{\Phi}(t)$

$$
U_{0}^{\Phi}\left(P_{I}^{\Phi}, t\right)=V_{0}^{U}\left(P_{I}^{\Phi}, t\right)-V_{0}^{U}\left(P_{I}^{\Phi}, t\right) *+U_{0}^{\Phi}\left(P_{I}^{\Phi}, t\right) *
$$

\footnotetext{
${ }^{20}$ Although underinvestment effects of debt financing of investment options may seem counterintuitive, they might happen for extremely large levels of debt financing when the marginal bankruptcy costs largely exceed the marginal tax shields, making it costlier to invest. This situation only happens for levels of leverage that largely exceed the optimal debt target. These costs arise when investors have serious financial constrains.
} 
Boundary condition (14.b) represents overinvestment costs prior to expiry of the investment option. They represent the loss of insurance value and increased impact of the time value of money effect of the investment cost (remember that the option to invest configures itself as an American call). Condition (15.b) ${ }^{21}$ represents underinvestment effects where they reflect the loss of operational cash flow due to delaying investment. Note that boundary (14.b) does not incorporate future overinvestment costs because investing earlier in the levered case kills the investment option. In the underinvestment case, boundary (15.b), by delaying investment in the levered case, the option remains alive accruing all future costs of suboptimal policies $U_{0}^{\Phi}\left(P_{I}^{\Phi}, t\right) *$.

\subsubsection{Optimal debt levels and fair rates}

The face value of debt in the first $\left(F^{F}\right)$ and second-best policies $\left(F^{S}\right)$ are solutions to the following maximization problems,

$$
\begin{aligned}
& \underset{F^{F} \in[0, I[}{\operatorname{Max}}\left\{V_{0}^{F}\left(P, t_{0}\right)\right\} \\
& \underset{F^{S} \in[0, I[}{\operatorname{Max}}\left\{V_{0}^{S}\left(P, t_{0}\right)\right\}
\end{aligned}
$$

For both investment option exercise policies ${ }^{22}, F^{\Phi}$ represents the amount of debt that maximizes the value of the option to invest on a levered firm at time $t_{0}$, since it represents the moment when the commitment loan is agreed and the amount $F^{\Phi}$ is defined. In no case can $F^{\Phi}$ be greater than the value of $I$. This assumption is not very limiting, since the optimal amount of leverage would only be greater than the cost of investment in a very favourable tax system.

At time $t_{0}$ the value of $r_{d}^{\Phi}$ is also defined. The fair rate $r_{d}^{\Phi}$ is such that for the amount of debt $F^{\Phi}$ the value of $D_{0}^{\Phi}\left(P, t_{0}\right)=0$.

\subsection{Agency costs}

This section defines the agency costs of debt beginning with their simplest expression,

$$
A=V_{0}^{F}-V_{0}^{S}
$$

\footnotetext{
${ }^{21}$ The superscript * represents the diffused values for $V_{0}^{U}$ and $U_{0}^{\Phi}$, if the value-matching boundary condition for exercise of the investment option in the unlevered case was not enforced.

${ }^{22}$ Since the maximization problem is similar for both policies, we make use of the superscript $\Phi$ for the sake of simplicity.
} 
It is important to notice that there is no mispricing of the debt claims, contrary to other conflicts, and there is no explicit wealth transfer effect occurring. Equityholders do not consciously try to expropriate debtholders of their wealth by making extraordinary dividend payments or by in any other way reducing the asset basis of the firm. The main cost is different, and it is "paid" by the economy at large. The difference in firm value between both policies represents the economic cost of not obtaining the maximum profitability out of a specific set of assets. It should be reminded however, that this need not involve any unforeseen or unpriced transfer of wealth from debtholders to equityholders.

In order to better understand where the loss in value comes from we begin by analysing the impact of debt financing on the value of the investment option.

$$
\begin{aligned}
& V_{0}^{F}=V_{0}^{U}+S_{0}^{F}-B_{0}^{F}-K_{0}^{F}-O_{0}^{F}-U_{0}^{F} \\
& V_{0}^{S}=V_{0}^{U}+S_{0}^{S}-B_{0}^{S}-K_{0}^{S}-O_{0}^{S}-U_{0}^{S}
\end{aligned}
$$

Expressions (18.a) and (18.b) relate the value of the same option to invest in an unlevered firm $\left(V_{0}^{U}\right)$ to the case where investment is realized in a levered firm $\left(V_{0}^{S}, V_{0}^{F}\right)$.

The combination of expression (18) with expressions (18.a) and (18.b) allow us to divide the agency costs between ${ }^{23}$ :

$$
A=A^{\Gamma}+A^{\Omega}
$$

where,

$$
\begin{aligned}
& A^{\Gamma}=\left(S_{0}^{F}-S_{0}^{S}\right)-\left(B_{0}^{F}-B_{0}^{S}\right)-\left(K_{0}^{F}-K_{0}^{S}\right) \\
& A^{\Omega}=-\left(O_{0}^{F}-O_{0}^{S}\right)-\left(U_{0}^{F}-U_{0}^{S}\right)
\end{aligned}
$$

$A^{\Gamma}$ comprises the direct costs of debt financing such as loss of interest tax shields or increased bankruptcy costs, a direct consequence of leverage on the value of the firm. $A^{\Omega}$ comprehends the operational opportunity costs, resulting from the changes in the investment option exercise boundary as a result of the agency conflicts. One further difference between both costs concerns their source. $A^{\Gamma}$ occur at firm level whereas $A^{\Omega}$ arise at the investment option level. This degree of detail in the analysis of agency costs is essential in order to fully understand their nature in a fixed life project.

\footnotetext{
${ }^{23}$ To decompose the agency costs between financial and operational is common in the agency theory literature $A^{\Omega}$ represents operational costs, following Myers (1977, pg 149) which defines $A^{\Omega}$ as the "costs of the suboptimal future investment strategy."
} 


\section{Numerical Analysis}

Table 1 presents the base case parameters and a brief discussion of these parameters is also provided. All the arbitrarily determined parameters are as similar as possible to the ones used in previous research for comparison purposes.

\section{[INSERT TABLE 2]}

What follows is an analysis of a case with a maturity of 2 years for an investment option on a firm that operates a concession during 8 years. This period is slightly shorter than the average oil or public utility concession, but still higher than most image or audiovisual rights contracts.

As far as the bankruptcy costs are concerned, they incorporate both the direct costs of distress and costs of disrupt of the normal business activities. It is not easy to present an accurate estimate of these costs due to the wide variability of the empirical results. As Gupton et al. (2000) point out, the wide spread on the estimations of bankruptcy costs and recovery rates is a source of frustration for credit risk modellers and investors. In the base case they are assumed to represent $40 \%$ of the unlevered firm value, as it falls in the range of recovery rates empirically observed (as high as $86 \%$ by Franks and Torous, 1994, and $90 \%$ by Andrade and Kaplan, 1998, and as low as $47 \%$ by Gupton et al., 2000). These estimates were produced for bank loans, while other types of debt the bankruptcy costs tend to be higher. According to Dahiya et al. (2003), bank loans are typically considered as senior debt and are in most cases secure. In this case they are the only source of debt financing, are unsecured and finance a fixed life asset. Hence, the base-case figure of $40 \%$ is somewhat above the lower bound of empirically observed rates of recovery.

The issuance costs are assumed to be $0 \%$ for the base case although later they are extended to $4 \%$ of the face value of debt. They consist of bank fees, legal fees and other transaction costs. This figure may seem relatively high for a bank loan when compared with underwriting spreads (Drucker and Manju, 2005); nevertheless the underwriting fee does not reflect entirely the remuneration of the underwriter because part of it is reflected in the credit spread, however in this model the credit spreads only reflect the default risk of the firm and the costs arising from moral hazard. According to Krishnaswami et al. (1999) private lenders have an informational advantage over public lenders ${ }^{24}$; therefore the model does not reflect on the credit spread any adverse selection costs. Instead, it assumes that the

\footnotetext{
${ }^{24}$ Best et al (1993) support this hypothesis with empirical evidence.
} 
bank has non-public information regarding the future potential of the concession and it is aware of the volatility of the returns on the cash flows.

Regarding the growth rate of the investment costs, the base-case assumes a value of $0 \%$. In later stages different scenarios are considered where this cost evolves at the inflation rate (the rates considered will always be inferior to the risk free rate since they represent ex-ante estimates (see Kandel at al, 1996)).

\subsection{Option to default and the different debt repayment schedules}

The analysis includes, probably the two most common long-term repayment methods. A constant amortization schedule (CA) and a constant repayment (CR) schedule. Both debt repayment schedules have their advantages and disadvantages and in most cases one schedule is able to accommodate better the characteristics of the market and of the underlying asset, optimizing the value of the option to invest.

The CA schedule presents a lower average leverage ratio during the life of the loan, since the principal is repaid more rapidly when compared to the CR schedule (Graph 1). Thereby, it incurs less total interests over the life of the loan generating lower interest tax shields of debt. After a higher financial effort in the first moments ${ }^{25}$, debt service is considerably reduced relatively to the $\mathrm{CR}$ schedule (given of the lower amount of debt outstanding), where the effort is constant through the life of the loan.

\section{[INSERT GRAPH 1]}

The default boundaries for both debt schedules reflect exactly the differences between both debt schedules as it becomes clear from the analysis of Graph 2.

\section{[INSERT GRAPH 2]}

The CA schedule initially presents a higher default boundary as a consequence of the higher effort required to meet the constant amortization plan. In the first moments, since the cashflows to debt in the CA schedule are higher, they also exhaust earlier the value of equity forcing it to default sooner. However, if the firm is able to meet the initial higher repayment requirements for the $\mathrm{CA}$ schedule, default is much less likely to occur than in the $\mathrm{CR}$ schedule. This is a consequence of the higher average debt levels in the CR schedule. In the CR schedule after the initial moments, the higher effort required to meet debt payments (due to the higher levels of debt outstanding and the consequently higher interest rate) induces

\footnotetext{
${ }^{25}$ Higher initial debt repayments do not always agree with a start-up business where liquidity is often scarce when it starts operating.
} 
equity to default earlier (or at higher values of the underlying) when compared with the CA schedule.

When able to meet the required payments the CR schedule generates significantly higher interest tax shields of debt since it also remunerates debt with higher interest rates.

Graph 2 portrays what happens in the lower end of the spectrum of future possible values of $P$. To put things in perspective, the likelihood of default must be analysed. For the CA schedule (which has the highest default boundary in the first years of operation) default occurs when $P=33$. In the worst case scenario investment occurs at the lowest possible value of $P=124$, so, in the CA case, for default to occur during the first 2.3 years of operation (when CA has a higher default boundary relatively to $\mathrm{CR}$ ), the market value of $P$ has to drop roughly $73 \%$, something unlikely to occur to say the least. When the default boundary for CR steadily increases after the 6th year, the concession runs only for two years more. Thereby, the higher cash-flows the CR schedule generated (because of the higher tax savings) during 6 years, substantially mitigate the higher bankruptcy costs the CR schedule has when compared to CA. This is the reason why the differences between the values of the investment option for both schedules at the optimal debt levels can never differ to much.

\subsection{Debt financing, agency conflicts and the investment decisions}

This section focuses on the impact of debt financing and the existence of agency conflicts on the investment decisions. The impact of debt financing is perceived by the shift in the investment boundary from the unlevered case to the first-best levered case. Similarly, the impact of debt financing is perceived by the shift in the investment boundary from the firstbest case to the second-best. The change in the investment boundary in the second-best case reflects the incentives decision makers have when they objectives of equity value maximization rather than firm value maximization.

\section{[INSERT GRAPH 3]}

By following a first-best policy of firm value maximization, investors have the incentive to move faster and invest earlier, relatively to the unlevered firm in order to capture the additional income provided by the interest tax shields.

In the second-best investment policy, the overinvestment effects relatively to the unlevered case are smaller. In other words, following a second-best policy investors underinvest relatively to a first-best policy $P_{I}^{F}\left(t<T^{I}\right)<P_{I}^{S}\left(t<T^{I}\right)<P_{I}\left(t<T^{I}\right)$. These underinvestment incentives are very similar to the debt overhang problem described by Myers (1977). Equity 
delays the exercise of the investment option in order not to share the benefits of the investment with the debtholders when equity bears a significant part of the costs. The definition of the optimal exercise boundary in the second-best policy balances several positive and negative effects. By exercising earlier (or closer to the first-best boundary) equity starts receiving dividends earlier and it also partially transfers the default risk to debtholders, in the event of bankruptcy, due to its limited liability (Mauer and Sarkar, $2005)^{26}$. On the other hand it shares part of the benefits with debtholders reducing its risk exposure and increases the probabilities of having to cover for any shortfall in the interest payments. By investing to early it also loses the value of waiting and the guarantee value provided by the option. In this case, the second effects dominate the first and the secondbest policy underinvests relatively to the first-best policy. However, these results cannot and should not be generalised to all the cases where investment options are partially financed with commitment loans. A mere increase in the pay-out ratios ${ }^{27}$, or the possibility of financing shortfalls on interest payments with new debt or disinvestments would be sufficient to extend the overinvestment incentives from maturity to the full life of the option $^{28}$. However, and similarly to results reported by Mauer and Triantis (1994), the operational impact of this distortions in the investment policy prior to expiry of the investment option, are only marginal as reflected by the value of the overinvestment effects for the first-best policy reported in table2.

Although Graph 3 one does not present it explicitly, at expiry of the investment option the situation is very different. At expiry, the decision does no longer refer to the timing of investment, rather to whether investment itself should take place or not. In this case, investors following a second-best policy, which were taking a more prudent approach when analysing the investment decisions away from expiry, now take on a very aggressive overinvestment approach as the option expires $P_{I}^{S}\left(T^{I}\right)<P_{I}^{F}\left(T^{I}\right)<P_{I}\left(T^{I}\right)$. These effects have a greater impact on the value of the option than anything that happens prior to expiry. By underinvesting before maturity following a second-best policy, investors lose a portion of the tax shield effects of debt financing. By overinvesting at maturity they significantly expropriate debt of part of their wealth. At the investment option level, the present value of

\footnotetext{
${ }^{26}$ Upon default debtholders bear the full bankruptcy costs, however, prior to default, debtholders receive the interest payments they are entitled to, and equity bears the cost of covering for any shortfall. This is the reason why we mentioned that the default risk is 'partially' transferred.

${ }^{27}$ For a detailed analysis of early exercise features please see Subrahmanyam (1990).

${ }^{28}$ The effect of the guarantee value of the option is only marginal because of the aggressive overinvestment incentives equity have at the maturity of the investment option.
} 
the underinvestment effect is thereby much smaller than the overinvestment. The overinvestment incentive, as anticipated by creditors, also induces higher credit spreads, lowers the debt capacity consequently lowering the positive impact of debt financing. Section 2.2.2 presented the rational underlying these incentives, however in section 3.3 it is analysed with more detail.

\section{[INSERT TABLE 3]}

This problem represents a situation where two different types of incentives coexist during the life of the option to invest. It is not common to find the simultaneous existence of two different incentives (overinvestment and underinvestment) in a single framework (investment option) analysing one single conflict (equityholders-debtholders). To our knowledge Mao (2002) is the only paper reporting similar evidence. However, in his case it was built into the model by considering growing marginal volatility of investment ${ }^{29}$, where in our case it represents a result.

Although two incentives coexist, only one significantly impacts the value of the option to invest and it occurs at the expiry moment of the option to invest. These results give some relevance to arguments of previous research, focusing on the interactions between investment and financing decisions, where European profiles for the real options were considered.

\subsection{Analysis at expiry of the investment option $T^{I}$}

Prior to expiry of the investment option, investors face the choice between investing or delaying investment. At expiry, the decision becomes whether to invest or not, either exercise the option or let it expire worthless. This represents the moment when the impact of the agency conflicts is more severe.

This framework considers the investment decision as an American option, however it is not always the case in concession contracts. Most public utility concessions configure themselves more like a European option, since the concession is obtained by submitting a public bid. The analysis of the expiry moment helps understand why considering similar operational efficiency, different financial structures and different sensibilities to agency conflicts may explain different biding prices for public utility concessions.

\footnotetext{
${ }^{29}$ It is arguable that this might simply represent a risk shifting case.
} 
Graph 4 represents the values of the unlevered firm, levered firm, equity and debt at expiry of the option to invest. It also included the cost of investment, the optimal amount of debt financing for the first-best policy and the difference between the cost of investment and the face value of debt (since it represents the cost of investment for equity).

\section{[INSERT GRAPH 4]}

For the base case parameters, the optimal amount of leverage is 23.75 representing $47.5 \%$ of the total cost of investment. For a $P$ value of 100 at $t_{0}$ the fair rate $r_{d}^{F}$ that makes $D_{0}^{F}\left(100, t_{0}\right)=0$ is $7.6 \%$. For the unlevered case, investment occurs for values of $P$ greater or equal to $131.2\left(P_{I}=131.2\right)$ and for levered case following a first-best policy investment occurs for values of $P$ greater or equal to $130.8\left(P_{I}^{F}=130.8\right)$. Although operationally the decision to invest at a negative operational $N P V$ might sound irrational, it is perfectly rational due to the fact that the negative operational $N P V$ value of -.137 $\left(V^{U}\left(130.8, T^{I}\right)-I\right)^{30}$ is compensated by the positive difference between the present value of the interest tax shields and the bankruptcy costs of debt.

However, given the impossibility of writing up a contract that commits equityholders not to invest at a lower value than 130.8 for the underlying asset (with very few exceptions, real options are not quoted and the costs for debtholders of tracking the market for $P$ and monitoring equityholders' behaviour would be prohibitively high), at expiry, rational equityholders are willing to invest at 127.8. It is rational for them to do it because the overinvestment costs of 1.357 are more than compensated by the positive difference between the present value of the interest tax shields and the bankruptcy costs of debt and the negative $N P V$ to debt. By investing at such a low value they are effectively transferring the costs of default to debtholders, while retaining the upside potential of upward movements in $P^{31}$.

Debtholders rationally anticipate this behaviour and assume that equityholders would invest at values of $P$ lower than 130.8 , they thereby require an interest rate higher than $7.6 \%$ to make the debt contract fair. By requiring a higher rate, debtholders make debt less attractive. Thereby, the optimal debt level for the second best policy is 22.25 , representing $44.5 \%$ of

\footnotetext{
${ }^{30}$ Naturally, this value represents the overinvestment costs at expiry of the investment option for the first-best case.

${ }^{31}$ This case reflects Jensen and Meckling (1976) and Myers (1977) conclusions regarding the exercise of investment options with negative $N P V$.
} 
the cost of investment with an interest rate of $7.5 \%{ }^{32}$ (it represents a decrease of $6 \%$ in the optimal debt level). At maturity with $F^{S}=22.25$ and with $r_{d}^{S}=7.5 \%$ equityholders are willing to invest for values of $P$ greater or equal to $124.0\left(P_{I}^{S}=124.0\right)$ at which point the overinvestment costs are 2.73 .

Return now to the example of a bid for a public utility concession. Consider that the concession would be assigned to the bid in which the concessionaire would commit himself to invest more in the renovation or expansion of the public infrastructure ${ }^{33}$. Although this does not represent an objective of this work it becomes clear from the analysis of the different investment triggers at expiry of the investment option, $\left(P_{I}^{S}<P_{I}^{F}<P_{I}\right)$, how the existence of debt financing and of agency conflicts may explain why, given similar operational efficiency, it is rational for some firms to submit bids that may look irrational otherwise.

\subsection{Agency Costs}

The first obvious conclusion from the analysis of Table 4 concerns the fact that agency costs of debt are always higher in the CR schedule relatively to the CA schedule. The fact that default is more likely to occur later in time, due to the significant difference between the asset value at which investment occurs and the asset value at which equity defaults, makes it more likely to occur in the CR schedule. Even considering adverse movements in $P$ it will take some time for the losses to exhaust the value of equity. This fact reduces the relative advantage of the CR schedule over the CA schedule in the initial moments after investment occurs. Thereby in the CR schedule, at expiry of the option to invest, equityholders are willing to invest at lower values of the underlying because they can transfer a higher default risk to debtholders when compared with the CA schedule.

\section{[INSERT TABLE 4]}

Higher volatility of the underlying asset increases the value of the options, however, a riskier asset also generates higher agency costs of debt financing. The positive relationship between the agency costs of debt and the volatility of the assets relates to the increased incentives it gives equityholders to overinvest at expiry of the option to invest. With low

\footnotetext{
${ }^{32}$ The lower interest rate is explained by the lower debt ratio for the second-best policy, for the same amounts of debt financing the interest rate is naturally high in the second-best policy.

${ }^{33}$ In this framework $I$ would become a variable endogenous to the model, which would maximize the values of $V_{0}^{U}, V_{0}^{F}$ and $V_{0}^{S}$ at $t_{0}$. Although it represents an interesting problem it is beyond the scope of this work and it would require considering competition to make it realistic.
} 
volatility, the value of the option to default is very low, since bankruptcy is very unlikely to occur. With riskier assets, default becomes a real possibility and equity is willing to invest at lower values of the underlying since it can transfer most of the default risk to debtholders while retaining the upside potential (due to limited liability and the fixed nature of debts' claim). The increase in the value of waiting to invest encourages equity to delay investment, thereby increasing the underinvestment costs and increasing the probability of exercising the investment option at expiry at negative $N P V$ values. For riskier assets the increase in the agency costs is bigger than the increase in the value of the option to invest. The impact of different risk levels on the agency costs of debt, confirms the results of Leland (1998) and Childs et al. (2005), where increased volatility is accompanied by increasing agency costs. However, these results contradict the findings of Mauer and Sarkar (2005), although both settings portray an option to invest in a risky project. In both cases higher volatility translates in delayed investments in both policies ${ }^{34}$, but contrary to our results, the authors report an inverse relationship between volatility of the underlying asset and the agency costs of debt. As expiry of the option to invest approaches, the fact that this framework collapses into a 'now-or-never' decision, translates into a significant increase of the overinvestment costs at expiry of the option, which may help explain the differences between this results and those from Mauer and Sarkar (2005).

Similarly to Leland (1998), this results indicate that changes in the pay-out ratios have little impact on the agency costs, since higher pay-out ratios increase significantly the value of the option to invest, the agency costs of debt are relatively less important for higher values of $\alpha$.

For assets with rapidly growing costs of investment the value of the option to invest is lower when compared with assets where the cost of investment remains stable over time because the expected cost of investment is higher. However, the agency costs are lower for assets with rapidly growing costs of investment. Before, it was reported that the moment where most of the agency costs of investment are generated is at expiry of the option to invest. With growing costs of investment investors have the incentive to anticipate investment and this makes it less likely that investment will occur at expiry of the investment option.

The higher the issuance costs the lower is the value of the option to invest in a levered firm and the agency costs of $\mathrm{debt}^{35}$. Higher issuance costs reduce the incentives to overinvest at expiry of the investment option because they make investment more expensive for the

\footnotetext{
34 As evidenced by the lower overinvestment effects for the first-best policy and higher underinvestment effects for the second-best policy.

${ }^{35}$ Similar results were reported by Childs et al. (2005) in their static financing case.
} 
levered firm. For very high issuance costs investment becomes so expensive for the levered firm that investors will underinvest relatively to the unlevered firm. However, even in this case the agency costs of debt will not increase, because the impact of a higher $\kappa$ in the incentives of the investors is the same whether they aim at maximizing firm value or equity value. However, for high issuance costs, the composition of the agency costs will be different. The degree of underinvestment will be greater in the first-best policy relatively to the second-best where the investment boundary will be closer to the operationally optimal, and the present value of the issuance costs will be larger in the second-best policy since investment is more likely to occur earlier.

Higher bankruptcy costs have a negative impact on the value of an option to invest on a levered firm, and a positive impact on the agency costs of debt. A costlier bankruptcy procedure has a greater impact on the debt claim than on the equity claim given its limited liability. Therefore, the fair interest rate is also much higher in the second-best policy as the bankruptcy costs increase. Although the incentives to invest at lower values of the asset are reduced, they are not completely eliminated, and the consequential higher interest rate, in the second-best case, makes bankruptcy much likelier to occur (higher interest repayments exhaust the value of the equity claim faster). Contrary to the agency costs when bankruptcy procedures destroy less value of the firm, which are entirely born of the loss of pure operating value due to suboptimal investment decisions, when bankruptcy is expensive the agency costs reflect entirely the fact that bankruptcy is much more likely to occur.

On the other extreme there is a positive impact of the corporate tax rate on the value of the option to invest on a levered firm. Higher corporate tax rates also generate lower agency costs of debt. Although with higher tax rates, investment is more likely to occur at a lower asset value for both the first-best and the second-best policies, the likelihood of default is reduced via the increase of income through higher tax savings. For high corporate tax rates, the present value of the higher tax savings in the second-best policy (given the higher interest rate) more than compensates the bigger incentive to invest at values clearly below what would be operationally optimal.

The risk free rate influences the opportunity cost of not deferring the payment of the investment costs, so, the higher the risk free rate the smaller are the incentives to invest earlier. This delay in investment makes it more likely to occur at expiry of the investment option. However, the financial impact of a higher $r$ in terms of increased debt tax shields and reduced bankruptcy costs more than compensates the increase in the operational component of the agency costs. Analysing the agency costs as a proportion of the value of the option to 
invest, the reduction becomes more obvious because of the positive impact of high interest rates in the value of the option to invest. Mauer and Sarkar (2005) report a similar impact of higher risk free rates on the size of the agency costs of debt.

The time to expiry of the option to invest has an influence similar to the risk free rate. As the time to expiry increases so does the opportunity cost of investing earlier in terms of the time value of the cost of investment. Similarly, the insurance value of the option also rises, because there is a greater probability of being able to invest at better market conditions. On the other hand there is also a greater probability that, at expiry of the investment option, it will not be optimal to invest. Thereby, for higher $T^{I}$ the probability of investing at expiry of the investment option increases. However, the positive impact of higher $T^{I}$ on the value of the option is larger than the rise in the agency costs of debt, therefore the relative impact of the agency costs for higher $T^{I}$ is much smaller.

The last parameter considered is the tenor of the concession contract, the longer its life expectancy the higher will be the value of the concession itself. As the value of the concession increases so do the probabilities of early exercise, the investment boundary shifts downward. For higher $T^{C}$ when investment occurs at expiry of the option to invest it will also occur at much lower values of $P$. Although somewhat limited by the higher probabilities of early exercise, the size of the overinvestment costs, at expiry of the option to invest, is much larger for longer life concessions. When considering the relative importance of the agency costs, they lose some impact, given the rise in value of the option to invest. Although agency costs grow with $T^{C}$ they are relatively less significant.

\subsection{Optimal debt levels}

This section analyses how different market conditions and different asset characteristics influence the choice of optimal debt levels and the agency costs.

\section{[INSERT TABLE5]}

From a first analysis of Table 5 it immediate stands out that the higher is the debt capacity of the firm the higher are the agency costs of debt. This result is interesting since it reflects a direct positive relationship between leverage ratios and agency costs of debt. Several papers (e.g. Leland, 1998) have tried to analyse the existence of a positive relationship between debt levels and agency costs, something that this results overwhelmingly support. One other aspect common in all the different market and asset scenarios considered, is how agency conflicts reduce the debt capacity of firms. The debt capacity of the policy of firm value 
maximization is always bigger than that of the policy of equity value maximization and sometimes these differences are significant.

The optimal debt target is higher for very risky assets and for assets with very low risk. The $\mathrm{U}$ shape of the optimal debt target to different levels of risk can be explained in the following way. The less risky the asset is the lower are the expected bankruptcy costs and the bigger is the positive impact of debt (difference between the interest tax shields and the bankruptcy costs of debt). Naturally for low risk assets the operational component of the agency costs will be larger, since the financial incentives significantly lower the optimal investment exercise boundary relatively to the unlevered firm value. As volatility increases, debt becomes less attractive due to rapidly growing bankruptcy costs. However, the growing bankruptcy costs become less significant (reduced marginal bankruptcy costs) as the increase in volatility significantly increases the investment option value. The change occurs at the minimum target debt ratio (between 30\% - 50\% volatility). In the second-best investment policy the rise in the optimal debt level is much less pronounced, because higher volatility significantly increases the agency costs of debt. By increasing the value of the option it encourages equity to delay the investment exercise moment, thereby increasing the underinvestment costs and increasing the probability of investing at negative $N P V$ values at expiry. In other words, increases in volatility, by exacerbating suboptimal investment choices by equityholders, limit the growth of the target debt ratio and eliminate the positive effect of the higher investment option values ${ }^{36}$. It is interesting to observe how the nature of the agency costs shifts as volatility increases. At low levels of volatility the agency costs are born essentially from operational effects, for high values of volatility, the direct financing effects represent a significant part of the agency cost in terms of the loss of interest tax shields due to the increase in the difference between the optimal debt target ratios for the first-best and second-best policies.

Higher pay-out ratios present lower optimal debt levels for both policies, however, the difference between both debt targets also becomes smaller, thereby the agency costs at the optimal debt levels are also much smaller.

Different growth rates for the investment costs do not seem to impact significantly the optimal debt levels. Higher growth rates present slightly higher optimal levels of debt, however the effect they have on the debt capacity of the firm is not very clear.

\footnotetext{
${ }^{36}$ Leland (1998) and Childs et al. (2005) report similar findings concerning the changes in the optimal debt levels.
} 
As expected, higher issuance costs of debt reduce the optimal debt targets, by making debt financing more expensive and thereby less attractive. In terms of agency costs, they represent a decreasing function of the issuance costs. Similar results were reported by Childs et al. (2005) in their static financing case. For sufficiently high issuance costs the agency costs are eliminated. The decrease in the optimal debt target produces these results (less debt, less agency conflicts). However significant the reduction in agency costs is, issuance costs do not represent a viable moral hazard control mechanism. It is obvious from the analysis of the impact of higher values for $\kappa$ in the investment option value, the reduction in value largely exceeds the value of the agency costs of debt when $\kappa=0$. Also, growing issuance costs do not reduce the incentives equity has to overinvest, they merely make it costlier to overinvest ${ }^{37}$.

Bankruptcy costs have a similar impact. Higher bankruptcy costs of debt reduce the optimal debt target for both policies, ultimately levelling them out. The reduction in the optimal debt levels induces a reduction on the agency costs as the investment boundaries converge. Similarly, lower corporate tax rates also reduce the agency costs by making debt less attractive. For low levels of debt, overinvestment incentives are marginal and debt has very low risk. Analogous results are reported in Leland (1998), Mauer and Sarkar (2005) and Childs et al. (2005) concerning the relationship between bankruptcy costs, corporate tax rates, debt levels and agency costs.

Higher risk free rates increase the value of the option to invest, thereby making it more likely that the investment option will be exercised at higher values of the underlying asset (increased debt capacity). However it also makes it more likely that investment may occur at expiry at the investment option at negative operational $N P V$ values. Something that is reflected in the higher agency costs of debt for higher risk free rates. Mauer and Sarkar (2005) also report similar impacts of increased risk free rates on both the optimal leverage and agency costs.

The impact of a longer life for the option to invest is similar to the impact of higher risk free rate, since it increases the value of waiting. It delays investment making it more likely to occur at higher values of the asset and thereby raising the optimal debt level. Although the higher value of waiting also increases the possibility of investment occurring at expiry, the

\footnotetext{
${ }^{37}$ In a simple analogy think of the impact of issuance costs on the overinvestment problem as the impact of growing fees on a life insurance policy, they do not provide any incentives for clients to lead a healthier life, they simply make it more expensive for clients which are reckless to take up a life insurance policy.
} 
extended expiry date of the option reduces the probability that the investment option will reach expiry unexercised. The lower increase in the operational component of the agency costs reflects this fact.

Longer duration for the concession directly increases the value of the firm. Longer time operating the concession and accumulating the cash flows it releases. Thereby it is natural that the optimal debt levels are significantly higher for longer concessions.

Although it may seem intuitively appealing to assume that the differences between both repayment schedules could be eliminated by adjusting the initial debt level, this is not the case, as it becomes obvious from the analysis of Table 4 . The relative advantage of one debt schedule over the other relates to the balance between the interest tax shield advantage of CR over CA and its disadvantage in terms of higher bankruptcy costs of debt and higher agency costs. In the CR schedule default occurs at higher values of the underlying (bankruptcy costs are proportional to the value of $P$ ) and earlier loss of interest tax shields (upon bankruptcy the firm remains unlevered since it becomes property of the lender). However, the financial advantage in the RC schedule is generally bigger due to the higher value of interest tax shields it generates. Thereby, the more attractive debt is (the higher the optimal initial debt level $F^{S}$ ) the bigger the advantage of RC over CA, as reflected in Table 4 for all the parameters apart from cases of low volatility of the returns of $P$. For market conditions or asset characteristics where the optimal debt targets increase, the relative advantage of CR is such that even compensates the higher agency costs it generates.

For low volatility markets (for $\sigma<40 \%$ ), the difference between the lower value at which investors are willing to invest (at expiry of the investment option naturally) and the default boundary is smaller when compared with a more volatile market. Furthermore, since lower volatility flattens both the investment option exercise boundary and the abandonment boundary, both investment and abandonment will occur almost as the option to invest goes in-the-money (with no volatility there is little value for waiting) and exit with a lower fall in the asset value relatively to higher volatile markets ${ }^{38}$. In this situation, the schedule that guarantees a higher expected life for the firm becomes the most desirable. Thereby the

\footnotetext{
${ }^{38}$ Investors optimally abandon the market at higher values of $P$ relatively to more volatile markets, because when things are going bad and the market hardly moves, the 'hope of recovery' (present value of future expected cash-flows) does not compensate the effective losses equity suffers to avoid default.
} 
observed higher optimal debt level for the CA schedule, which is sufficiently higher to generate higher expected interest tax shields relatively to the CR schedule ${ }^{39}$.

\section{Conclusion}

While financing contracts remain incomplete, in the sense that they allow equityholders to adopt suboptimal investment policies while pursuing opportunistic objectives, agency relationships will remain a subject of interest. Contrary to the common perception, claiming that different types of real flexibility are generally associated with different incentives ${ }^{40}$, this analysis showed that different incentives (underinvestment and overinvestment) coexist in one single type of real flexibility (investment option). However, one type of incentive is clearly dominant; the impact of the overinvestment incentives on the value of the option to invest largely exceeds the impact of the underinvestment incentive confirming the conclusions of Mauer and Sarkar (2005). The results support the argument that this dominant effect usually occurs at maturity of the option providing some validity for research assuming a European profile for the investment option. To consider time constraints in a context of investment options reflects the reality of both commitment loans and many real investment opportunities.

For similar parameters this model presents predictions for the relative size of the agency costs lower then those predicted by previous research (e.g. Leland, 1998, Ericsson, 2000, Titman and Tsyplakov, 2002, Mauer and Sarkar, 2005, Childs et al., 2005), being particularly relevant the differences with Leland (1998), since the author do not take into account operational component of the agency costs. The differences are most likely linked with the time constraints for the investment option and the concession, because as the results demonstrate there is a positive relationship between the life of the investment option and of the concession and the agency costs of debt (more pronounced for the case of the life of the concession). Although the impact of agency costs at the optimal debt target is relatively low, given the size of most of the concession contracts the value the agency costs are always going to be significant and in the presence of budgetary constrains, forcing investors to take more debt than would be desirable, the agency costs are expected to grow rapidly.

\footnotetext{
39 The higher $F^{S}$ for $\mathrm{CA}$ is sufficiently high to compensate the higher interest rate and lower amortization rate of CR in generating higher interest tax shields.

40 For the case of growth options Mauer and Ott (2000) demonstrate how equityholders have the incentive to underinvest, for the case of investment options incentives Mauer and Sarkar (2005) show how equityholders have the incentive to overinvest.
} 
Agency costs reflect themselves in various levels and they are more complex than the mere difference of investment option values between different investment exercise policies. This paper proposes a way to divide them ${ }^{41}$ and shows the importance of not only analysing their size but also they constitution. It is especially important to understand and identify the source of the agency costs in order to try and mitigate them through more efficient contractual relationships.

The results at the optimal debt levels indicate that agency costs are more pronounced in conditions that optimize the use of debt financing: low bankruptcy costs, high corporate tax rates and high volatility markets. The model predicts a positive relationship between corporate tax rate, interest rate levels and growth rate of the investment costs with optimal debt levels. Inversely it predicts low levels of debt financing for markets with higher issuance or bankruptcy costs.

For the firms' decision makers the results evidence the importance of the choice of the debt repayment schedule to maximize the firm value. The different repayment schedules are not perfect substitutes and adjustments to the initial debt levels do not eliminate the attractiveness of one schedule over the other. At the optimal debt level one repayment schedule always tends to dominate the other. Overall, and although it is the one that generates more agency costs, the constant repayment schedule tends to be more attractive. The constant amortization schedule is more suitable when volatility is low, when the cash pay-out ratio is high and when debt financing is less attractive (high bankruptcy costs of debt or low corporate tax rates).

The impact of the financing mix and agency conflicts in the competitiveness of firms is an area where interesting results may be found. This model it is not the most appropriate to capture these implications but it leaves some clues that might motivate further research.

Even though, this area has been subject of recent interest by academics it still needs further theoretical work to clarify the nature of some relationships but especially empirical work that can shed some light in some of the discrepancies in the theoretical body of knowledge already developed.

\section{References}

\footnotetext{
${ }^{41}$ This paper takes an approach similar to Leland (1998) for the financial component and similar to Mauer and Sarkar (2005) in the separation between purely financial and operational effects.
} 
Andrade, G., and S. Kaplan, 1998, How costly is financial (not economic) distress? Evidence from highly leveraged transactions that became distressed, Journal of Finance 53, 1443-1493.

Barclay, M., C. Smith, and R. Watts, 1995, The Determinants of Corporate Leverage and Dividend Policies, Journal of Applied Corporate Finance 7, 4-19.

Best, Ronald, and Hang Zhang, 1993, Alternative Information Sources and the Information Content of Bank Loans, Journal of Finance 48, 1507-1522.

Bradley, M., G. Jarell, and Kim E., 1984, On the Existence of an Optimal Capital Structure: Theory and Evidence, Journal of Finance 39, 857-878.

Childs, P., D. Mauer, and S. Ott, 2005, Interactions of Corporate Financing and Investment Decisions: The Effect of Growth Options to Replace or Expand, forthcoming Journal of Financial Economics.

Dahiya, Sandeep, Anthony Saunders, and Anand Srinivasan, 2003, Financial Distress and Bank Lending Relationships, Journal of Finance 58, 375-399.

Drucker, Steven, and Puri Manju, 2005, On the Benefits of Concurrent Lending and Underwriting, Journal of Finance 60, 2763-2799.

Ericsson, Jan, 2000, Asset substitution, debt pricing, optimal leverage and maturity, Finance $21,39-70$.

Franks, J., and W. Torous, 1994, A comparison of financial recontracting in distressed exchanges and Chapter 11 reorganizations, Journal of Financial Economics 35, 349-370.

Gupton, Greg M. , Daniel Gates, and Lea V. Carty, 2000, Bank loan loss given default, Moody's Investors Service Global Credit Research Special Comment.

Jensen, M., and W. Meckling, 1976, Theory of the firm: Managerial behaviour, agency costs, and ownership structure, Journal of Financial Economics 3, 305-360.

Jou, Jyh-Bang, and Tan Lee, 2004, The agency problem, investment decision, and optimal financial structure, The European Journal of Finance 10, 489-509.

Kandel, Shmuel , Aharon R. Ofer, and Oded Sarig, 1996, Real Interest Rates and Inflation: An Ex-Ante Empirical Analysis, Journal of Finance 51, 205 - 225. 
Krishnaswami, Sudha, Paul A. Spindt, and Venkat Subramaniam, 1999, Information asymmetry, monitoring, and the placement structure of corporate debt, Journal of Financial Economics 51, 407-434.

Leland, Hayne E., 1998, Agency Costs, Risk Management, and Capital Structure, Journal of Finance 53, 1213-1243.

Long, M., and I. Malitz, 1985, The Investment-Financing Nexus: Some Empirical Evidence, Midland Finance Journal 53-59.

MacKay, P., 2003, Real Flexibility and Financial Structure: An Empirical Analysis, Review of Financial Studies 16, 1131-1165.

Mao, Connie X., 2002, Interaction of the Debt Agency Problems and Optimal Capital Structure: Theory and Evidence, Working paper, Fox School of Business and Management, Temple University, Philadelphia, PA.

Mauer, D., and S. Ott, 2000, Agency costs, underinvestment, and optimal capital structure, in M. J. Brennan, and L. Trigeorgis, eds.: Project flexibility, Agency, and Competition (Oxford University Press, New York).

Mauer, D., and S. Sarkar, 2005, Real options, agency conflicts, and financial policy, Journal of Banking and Finance 29, 1405-1428.

Mauer, David C., and Alexander J. Triantis, 1994, Interaction of corporate financing and investment decisions: a dynamic framework, Journal of Finance 49, 1253-1277.

Moyen, Nathalie, 2002, How Big Is the Debt Overhang Problem?, Working paper, University of Colorado.

Myers, S. C., 1977, Determinants of corporate borrowing, Journal of Financial Economics $5,147-175$.

Penfold, R., A. Batteson, and Jeremy Dickerson, 2005, How to defend image rights, Brand Management Focus 19-21.

Smith, C., and R. Watts, 1992, The Investment Opportunity Set, and Corporate Financing, Dividend, and Compensation Policies, Journal of Financial Economics 32, 262-292.

Subrahmanyam, Marti G., 1990, The early exercise feature of American options, in Stephen Figlewski, William Silber, and Marti G. Subrahmanyam, eds.: Financial Options - From theory to practice (McGrawHill, New York). 
Titman, Sheridan, and Sergey Tsyplakov, 2002, A Dynamic Model of Optimal Capital Structure, Unpublished Working Paper, University of Texas.

Veysey, Guy, 2002, Image rights and wrongs, Managing Intellectual Property 70-72. 


\section{Appendix 1: Derivation of the PDE and value function for $V^{U}$}

$P$ represents the present value of the perpetual expected after-tax cash flows of the asset underlying the concession, considering it all-equity financed. The market value of $P$ follows Geometric Brownian Motion, evolving according to the following process:

$$
d P=(\mu-\alpha) P d t+\sigma P d z
$$

where $\mu$ represents the drift rate, $\sigma$ represents volatility and $d z$ is the increment of a standard Wiener process. The pay-out rate $\alpha$ is assumed to be a constant proportion of $P$. The value of a concession contract $V^{U}$ to operate $P$ during $T^{C}$ can be represented as a function of $P$. Thereby applying Ito's lemma we have,

$$
d V^{U}=\left[\frac{1}{2} \frac{\partial^{2} V^{U}}{\partial P^{2}} \sigma^{2} P^{2}+\frac{\partial V^{U}}{\partial t}+\mu P \frac{\partial V^{U}}{\partial P}-\alpha P \frac{\partial V^{U}}{\partial P}\right] d t+\sigma P \frac{\partial V^{U}}{\partial P} d z
$$

Consider a portfolio $\pi$, consisting of a long position in $V^{U}$ and a $\Delta$ short position in the underlying asset $P$ or in a portfolio displaying the same risk characteristics of $P$ with a correlation coefficient of its returns with those of $P$ equal to 1 . The portfolio can then be represented by

$$
\pi=V^{U}-\Delta P
$$

with $\Delta$ being equal to,

$$
\Delta=\frac{\partial V^{U}}{\partial P}
$$

The change in value of portfolio $(d \pi)$ is described by equation (A4). It incorporates both the changes in the assets' values (capital appreciation) and the cash flows accruing to the holders of each of the assets,

$$
d \pi=d V^{U}+\alpha P d t-\Delta d P-\Delta \alpha P d t
$$

The owners of $V^{U}$ are entitled to the value of $V^{U}$ plus the cash flows it releases $(\alpha P d t)$. The owners of $P$ are entitled to a proportion $\Delta$ of the value of $P$ plus the cash flows it releases $(\alpha P d t)$.

In expression (A5) after replacing $d V^{U}$ by (A2), $d P$ by (A1) and $\Delta$ by (A4), all the terms with $d z$ and $\mu$ are cancelled out yielding the following expression, 


$$
d \pi=\left[\frac{1}{2} \frac{\partial^{2} V^{U}}{\partial P^{2}} \sigma^{2} P^{2}+\frac{\partial V^{U}}{\partial t}-\alpha P \frac{\partial V^{U}}{\partial P}+\alpha P\right] d t
$$

If portfolio $\pi$ is riskless in $d t$, by the law of one price and non-arbitrage arguments its return must equal the risk free rate $(r)$ in $d t$, thereby,

$$
d \pi=r \pi d t
$$

Substituting by equation (A6) on the left hand side, by equation (A3) and expression (A4) for $\Delta$ on the right hand side yields the partial differential equation (PDE) which solution represents the value of the unlevered firm $\left(V^{U}\right)$,

$$
\frac{1}{2} \frac{\partial^{2} V^{U}}{\partial P^{2}} \sigma^{2} P^{2}+\frac{\partial V^{U}}{\partial t}+(r-\alpha) P \frac{\partial V^{U}}{\partial P}-r V^{U}+\alpha P=0
$$

The value of $V^{U}$ must satisfy the following boundary conditions,

$$
\begin{aligned}
& V^{U}\left(P, T^{C}+t^{\prime}\right)=0 \\
& V^{U}(0, t)=0
\end{aligned}
$$

Expression (1.a) represents the terminal condition at $T^{C}+t^{\prime}$ when the concession contract expires and operations are terminated (the initial date the concession starts is $t^{\prime}$ ). It basically reflects the fact that there is no terminal value for the concession contract. Expression (1.b) represents the absorbing barrier at $P=0$.

We are looking for a solution of the form,

$$
V^{U}(P, t)=A(t)+B(t) P
$$

Representing the value of $V^{U}$ at a moment $t$, where $t^{\prime} \leq t<T^{C}+t^{\prime}$. By replacing the general solution into the PDE we get the following ordinary differential equation,

$$
\frac{d A(t)}{d t}+\frac{d B(t)}{d t} P-\alpha P B(t)-r A(t)+\alpha P=0
$$

This ODE can be divided between the elements which represent a function of time, and those which represent a function of time and the underlying,

$$
\frac{d A(t)}{d t}-r A(t)=0, \text { subject to } A\left(T^{C}\right)=0 \text { from boundary }(1 . \mathrm{a})
$$

and

$$
\frac{d B(t)}{d t}-\alpha B(t)+\alpha=0, \text { subject to } B\left(T^{C}\right)=0 \text { from boundary (1.a) }
$$

Thereby, for each moment $t$ (during the life of the concession) the value of $V^{U}(P, t)$ is, 


$$
V^{U}(P, t)=\left[1-e^{-\alpha\left(T^{c}+t^{-}-t\right)}\right] P
$$

At the moment $t$, when the option to invest in the concession is exercised the value of $V^{U}(P, t)$ is,

$V^{U}\left(P, t^{\prime}\right)=\left[1-e^{-\alpha T^{C}}\right] P$ 


\section{Appendix 2: Repayment debt schedules and interest tax shields}

This appendix derives the expressions for the value of the regular payments being made to debtholders comprehending interest and amortization. Additionally it presents th derivation for the value of the tax shields of debt regarding the interests being paid (since amortization payments are not tax deductible).

For $t$, where $t^{\prime} \leq t<T^{C}+t^{\prime}$ let:

$F=$ Initial face value of debt as defined in $t_{0}$

$r_{d}=$ Interest rate on the loan

$T^{\mathrm{C}}=$ Maturity of the loan

$N=$ Number of compounding and payment periods

$\tau=$ Corporate tax rate

$c\left(F, r_{d}, t, T^{C}\right)=$ Cash flows accruing to debt comprehending interest and amortization

$s\left(F, r_{d}, t, T^{C}\right)=$ Tax shields on the interests being paid

$d t=T^{C} / N$

\section{Constant debt repayment schedule (CR)}

We start by determining $c\left(F, r_{d}, t, T^{C}\right)$ from the well known formula for an annuity payment with $N$ simple interest payments, and determine the limit for the case where interest is continuously compounded,

$$
\frac{F r_{d}}{1-\left(1+r_{d} \frac{T^{C}}{N}\right)^{-N}} \frac{T^{C}}{N} \text { as } N \rightarrow \infty \text { the expression becomes, } \frac{F r_{d}}{1-e^{-r_{d} T^{C}}} d t
$$

In the derivation of the PDE's the $d t$ term is eliminated, so, the expression of the cash flows accruing to debt in the constant debt repayment schedule becomes:

$$
c\left(F, r_{d}, t, T^{C}\right)=\frac{F r_{d}}{1-e^{-r_{d} T^{C}}}
$$

The tax shields are not so simple because they represent a function on the amount of debt outstanding at moment $t$. Once again we start of with the simplest expression (from a simple interest formula) for the amount of debt outstanding at moment $n$-1 (where $0<n<N$ ). By multiplying it by $r_{d}$ and $\tau$ we get the value of the interest tax shields of debt. Next, we determine the limit for the case where interest is continuously compounded, yielding, 


$$
F \frac{T^{C}}{N}\left(\frac{1-\left(1+r_{d} \frac{T^{C}}{N}\right)^{-N+n}}{1-\left(1+r_{d} \frac{T^{C}}{N}\right)^{-N}}\right) r_{d} \tau \text { as } N \rightarrow \infty \text { becomes, } F r_{d} \tau\left(\frac{1-e^{-r_{d}\left(T^{C}+t^{\prime}-t\right)}}{1-e^{-r_{d} T^{C}}}\right) d t
$$

In the derivation of the PDE's the $d t$ term is eliminated, so, the expression of the interest tax shields of debt in the annuity case becomes,

$$
s\left(F, r_{d}, t, T^{C}\right)=F r_{d} \tau\left(\frac{1-e^{-r_{d}\left(T^{C}+t^{\prime}-t\right)}}{1-e^{-r_{d} T^{C}}}\right)
$$

\section{Constant amortization schedule (CA)}

Contrary to the CR schedule where debt cash-flows are constant over the life of the loan, in the CA schedule they are decreasing. Again we start with the expression for the simple interest case with $N$ amortization moments, and then determine the limit for the case where interest is continuously compounded. The value of the debt payment at moment $n$ (where $0<n<N)$ is,

$$
\frac{F}{N}+F\left(\frac{N-n+1}{N} r_{d}\right) \frac{T^{C}}{N} \text { as } N \rightarrow \infty \text { becomes, } \frac{r_{d}\left(T^{C}+t^{\prime}-t\right)+1}{T^{C}} F d t
$$

In the derivation of the PDE's the $d t$ term is eliminated, so, the expression of the cash flows accruing to debt in the continuously compounded constant amortization schedule becomes:

$$
c\left(F, r_{d}, t, T^{C}\right)=\frac{r_{d}\left(T^{C}+t^{\prime}-t\right)+1}{T^{C}} F
$$

Once again we start of with the simplest expression (from a simple interest formula) for the amount of debt outstanding at moment $n-1$ (where $0<n<N$ ). By multiplying it by $r_{d}$ and $\tau$ we get the value of the interest tax shields of debt. Next, we determine the limit for the case where interest is continuously compounded, yielding,

$$
F\left(\frac{N-n+1}{N} r_{d}\right) \frac{T^{C}}{N} \tau \text { as } N \rightarrow \infty \text { becomes, } F r_{d} \tau \frac{T^{C}+t^{\prime}-t}{T^{C}} d t
$$

In the derivation of the PDE's the $d t$ term is eliminated, so, the expression of the interest tax shields of debt in the CA schedule becomes,

$$
s\left(F, r_{d}, t, T^{C}\right)=F r_{d} \tau \frac{T^{C}+t^{\prime}-t}{T^{C}}
$$




\section{Figures}

Figure 1: Timescale of the model

\begin{tabular}{|c|c|c|c|c|}
\hline $\begin{array}{l}\text { Investors sign the } \\
\text { commitment loan } \\
\text { setting } F, r_{d} \text { and } T^{I}\end{array}$ & $\begin{array}{l}\text { Investment } \\
\text { option is } \\
\text { exercised }\end{array}$ & $\begin{array}{l}\text { Commitment loan } \\
\text { and investment } \\
\text { option expire }\end{array}$ & $\begin{array}{c}\text { Equity } \\
\text { Defaults }\end{array}$ & $\begin{array}{c}\text { Concession } \\
\text { Expires }\end{array}$ \\
\hline Option & est & Optio & $t^{\prime \prime}$ & $T^{C}+t^{\prime}$ \\
\hline
\end{tabular}




\section{Tables}

Table 1: Description of the assets the model values at firm and investment option levels

\begin{tabular}{|c|c|}
\hline Parameter & Description \\
\hline \multicolumn{2}{|r|}{ Firm level for $t$, where $t^{\prime} \leq t<T^{C}+t^{\prime}$} \\
\hline$V^{U}(P, t)$ & $\begin{array}{l}\text { Value of the firm operating the concession when investment is solely equity } \\
\text { financed }\end{array}$ \\
\hline$V^{\Phi}\left(P, F^{\Phi}, r_{d}^{\Phi}, t\right)$ & $\begin{array}{l}\text { Value of the firm operating the concession when investment is partially } \\
\text { financed with the proceedings from the commitment loan }\end{array}$ \\
\hline$E^{\Phi}\left(P, F^{\Phi}, r_{d}^{\Phi}, t\right)$ & Value of the equity claim on the levered firm \\
\hline$D^{\Phi}\left(P, F^{\Phi}, r_{d}^{\Phi}, t\right)$ & Value of the debt claim on the levered firm \\
\hline$S^{\Phi}\left(P, F^{\Phi}, r_{d}^{\Phi}, t\right)$ & Interest tax shields \\
\hline$B(P, t)$ & Bankruptcy costs of debt \\
\hline \multicolumn{2}{|r|}{ Investment option level for $t$, where $t_{0} \leq t \leq T^{I}$} \\
\hline$V_{0}^{U}(P, t)$ & Value of the option to invest on the unlevered firm \\
\hline$V_{0}^{\Phi}(P, t)$ & Value of the option to invest on the levered firm \\
\hline$E_{0}^{\Phi}(P, t)$ & Present value of $N P V$ to equity on the levered firm \\
\hline$D_{0}^{\Phi}(P, t)$ & Present value of $N P V$ to debt on the levered firm \\
\hline$S_{0}^{\Phi}(P, t)$ & Present value of tax shields of debt of the levered firm \\
\hline$B_{0}^{\Phi}(P, t)$ & Present value of bankruptcy costs of debt of the levered firm \\
\hline$K_{0}^{\Phi}(P, t)$ & Present value of issuance costs of debt of the levered firm \\
\hline$O_{0}^{\Phi}(P, t)$ & Present value of overinvestment costs of debt financing \\
\hline$U_{0}^{\Phi}(P, t)$ & Present value of underinvestment costs of debt financing \\
\hline
\end{tabular}

Table 2: Base case parameters

\begin{tabular}{|c|c|c|}
\hline Description & Parameter & Value \\
\hline $\begin{array}{l}\text { Present value of the perpetual expected after-tax cash flows of the asset } \\
\text { underlying the concession, considering it all-equity financed }\end{array}$ & $P$ & 100 \\
\hline Volatility of the returns on the cash-flow released by $P$ & $\sigma$ & $40 \%$ \\
\hline Cash flow rate of $P$ & $\alpha$ & $6 \%$ \\
\hline Corporate tax rate & $\tau$ & $20 \%$ \\
\hline Debt issuance costs & $\kappa$ & $0 \%$ \\
\hline Bankruptcy costs & $\delta$ & $40 \%$ \\
\hline Risk free rate & $r$ & $6 \%$ \\
\hline Growth rate of the costs of investment & $\gamma$ & $0 \%$ \\
\hline Cost of investment in the concession & $I$ & 50 \\
\hline Maturity of the investment option and commitment loan & $T^{I}$ & 2 years \\
\hline Life of the concession contract & $T^{C}$ & 8 years \\
\hline
\end{tabular}


Table 3: Value at time $t_{0}$ for the base case parameters of the options to invest in the firm operating the concession, the future equity and debt claims and debt effects considering the two different investment option exercise policy and the two debt repayment schedules. The bottom of the table presents the optimal debt levels and interest rates and the agency costs of debt.

\begin{tabular}{|c|c|c|c|c|c|}
\hline & \multirow{2}{*}{ Unlevered } & \multicolumn{2}{|c|}{ Constant amortization (CA) } & \multicolumn{2}{|c|}{ Constant repayment (CR) } \\
\hline & & First-best & Second-best & First-best & Second-best \\
\hline \multicolumn{6}{|c|}{ Investment option } \\
\hline$V_{0}\left(100, t_{0}\right)$ & 4.458 & 4.591 & 4.587 & 4.594 & 4.588 \\
\hline \multicolumn{6}{|l|}{ Debt Effects } \\
\hline$S_{0}^{\Phi}\left(100, t_{0}\right)$ & - & 0.244 & 0.235 & 0.291 & 0.273 \\
\hline$B_{0}^{\Phi}\left(100, t_{0}\right)$ & - & 0.110 & 0.100 & 0.155 & 0.135 \\
\hline$K_{0}^{\Phi}\left(100, t_{0}\right)$ & - & 0.000 & 0.000 & 0.000 & 0.000 \\
\hline$O_{0}^{\Phi}\left(100, t_{0}\right)$ & - & 0.000 & 0.006 & 0.000 & 0.009 \\
\hline$U_{0}^{\Phi}\left(100, t_{0}\right)$ & - & 0.000 & 0.000 & 0.000 & 0.000 \\
\hline \multicolumn{6}{|c|}{ Optimal leverage and price of debt } \\
\hline$F^{\Phi}$ & - & 23.750 & 22.250 & 24.500 & 22.250 \\
\hline$r_{d}^{\Phi}$ & - & $7.61 \%$ & $7.48 \%$ & $8.21 \%$ & $7.96 \%$ \\
\hline \multicolumn{2}{|l|}{ Agency costs } & value & $\% V_{0}^{S}$ & value & $\% V_{0}^{S}$ \\
\hline$A$ & - & 0.004 & $0.09 \%$ & 0.006 & $0.13 \%$ \\
\hline$A^{\Gamma}$ & - & -0.002 & $-0.04 \%$ & -0.003 & $-0.06 \%$ \\
\hline$A^{\Omega}$ & - & 0.006 & $0.13 \%$ & 0.009 & $0.20 \%$ \\
\hline
\end{tabular}


Table 4: Analysis of the impact of different market conditions and asset characteristics on the agency costs of debt considering a constant leverage ratio of $50 \%$ of the investment costs. We have not reflected the impact of the changes of the parameters on $P$. Although some parameters do not impact $P$, others, such as $\tau$ have an obvious impact on $P$. The results should not be analysed as sensitivity of the agency costs to changes in the parameters, but rather how different are the agency costs in different market conditions and for assets with different characteristics.

\begin{tabular}{|c|c|c|c|c|c|c|c|c|c|c|c|c|c|c|c|c|c|c|c|c|}
\hline \multirow{2}{*}{ Parameter } & \multirow{2}{*}{$V_{0}^{U}$} & \multicolumn{8}{|c|}{$\begin{array}{l}\text { Constant debt amortization }(\mathrm{CA}) \\
\end{array}$} & \multicolumn{8}{|c|}{ Constant debt repayments (CR) } & \multirow{2}{*}{\multicolumn{3}{|c|}{ 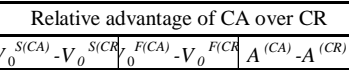 }} \\
\hline & & $r_{d}^{F}$ & $V_{0}^{F}$ & $r_{d}{ }^{s}$ & $V_{0}^{s}$ & $A$ & $A \%$ & $A^{\Gamma} \%$ & $A^{\Omega} \%$ & $r_{d}{ }^{F}$ & $V_{0}^{F}$ & $r_{d}^{s}$ & $V_{0}^{s}$ & $A$ & $A \%$ & $A^{\Gamma} \%$ & $A^{\Omega} \%$ & & & \\
\hline Base Case & 4.46 & $7.77 \%$ & 4.59 & $7.87 \%$ & 4.59 & 0.01 & $0.12 \%$ & $-0.06 \%$ & $0.19 \%$ & $8.29 \%$ & 4.59 & $8.45 \%$ & 4.58 & 0.01 & $0.21 \%$ & $-0.08 \%$ & $0.29 \%$ & 0.001 & $\begin{array}{ll}-0.003 \\
\end{array}$ & 0.004 \\
\hline$\sigma=10 \%$ & 0.06 & $6.00 \%$ & 0.08 & $6.00 \%$ & 0.08 & 0.00 & $0.00 \%$ & $0.00 \%$ & $0.00 \%$ & $6.01 \%$ & 0.08 & $6.01 \%$ & 0.08 & 0.00 & $0.00 \%$ & $0.00 \%$ & $0.00 \%$ & -0.002 & -0.002 & 0.000 \\
\hline$\sigma=30 \%$ & 2.60 & $6.91 \%$ & 2.74 & $6.94 \%$ & 2.73 & 0.00 & $0.07 \%$ & $-0.14 \%$ & $0.20 \%$ & $7.36 \%$ & 2.73 & $7.41 \%$ & 2.73 & 0.00 & $0.12 \%$ & $-0.14 \%$ & $0.25 \%$ & 0.008 & 0.007 & 0.001 \\
\hline$\sigma=50 \%$ & 6.40 & $8.33 \%$ & 6.55 & $8.56 \%$ & 6.53 & 0.01 & $0.22 \%$ & $-0.05 \%$ & $0.27 \%$ & $8.73 \%$ & 6.57 & $9.07 \%$ & 6.55 & 0.02 & $0.33 \%$ & $-0.10 \%$ & $0.43 \%$ & \begin{tabular}{|c|c|}
-0.011 \\
\end{tabular} & \begin{tabular}{|c|c|}
-0.018 \\
\end{tabular} & 0.007 \\
\hline$\sigma=70 \%$ & 10.15 & $8.11 \%$ & 10.35 & $8.73 \%$ & 10.31 & 0.04 & $0.39 \%$ & $-0.11 \%$ & $0.50 \%$ & $8.22 \%$ & 10.38 & $8.98 \%$ & 10.33 & 0.05 & $0.51 \%$ & $-0.22 \%$ & $0.73 \%$ & -0.018 & -0.030 & 0.012 \\
\hline$\alpha=3 \%$ & 0.53 & $6.42 \%$ & 0.57 & $6.54 \%$ & 0.57 & 0.00 & $0.30 \%$ & $\begin{array}{c}-0.38 \% \\
\end{array}$ & $0.68 \%$ & $6.47 \%$ & 0.58 & 6.63\% & 0.58 & 0.00 & $0.43 \%$ & $\begin{array}{c}-0.54 \% \\
\end{array}$ & $0.97 \%$ & \begin{tabular}{|l|}
-0.003 \\
\end{tabular} & \begin{tabular}{|c|}
-0.004 \\
\end{tabular} & 0.001 \\
\hline$\alpha=5 \%$ & 2.88 & $7.62 \%$ & 2.98 & $7.75 \%$ & 2.98 & 0.01 & $0.18 \%$ & $-0.09 \%$ & $0.27 \%$ & $8.04 \%$ & 2.99 & $8.22 \%$ & 2.98 & 0.01 & $0.27 \%$ & $-0.12 \%$ & $0.39 \%$ & $\begin{array}{l}-0.002 \\
\end{array}$ & \begin{tabular}{|c|}
-0.005 \\
\end{tabular} & 0.003 \\
\hline$\alpha=7 \%$ & $\begin{array}{l}6.17 \\
\end{array}$ & $7.83 \%$ & $\begin{array}{l}6.34 \\
\end{array}$ & $7.92 \%$ & 6.33 & 0.01 & $0.10 \%$ & $\begin{array}{l}-0.05 \% \\
\end{array}$ & $0.15 \%$ & $8.41 \%$ & $\begin{array}{l}6.34 \\
\end{array}$ & $8.56 \%$ & 6.33 & 0.01 & $0.18 \%$ & $\begin{array}{l}-0.06 \% \\
\end{array}$ & $0.24 \%$ & 0.005 & 0.000 & 0.005 \\
\hline$\alpha=9 \%$ & 9.74 & $7.88 \%$ & 9.97 & $7.97 \%$ & 9.96 & 0.01 & $0.09 \%$ & $\begin{array}{c}-0.04 \% \\
\end{array}$ & $0.13 \%$ & $8.56 \%$ & $\begin{array}{l}9.97 \\
\end{array}$ & $8.68 \%$ & 9.95 & 0.01 & $0.14 \%$ & $-0.05 \%$ & $0.19 \%$ & 0.010 & 0.005 & 0.005 \\
\hline$\gamma=1 \%$ & 4.29 & $7.70 \%$ & 4.42 & $7.79 \%$ & 4.41 & 0.01 & $0.12 \%$ & $-0.07 \%$ & $0.19 \%$ & $8.21 \%$ & 4.42 & $8.35 \%$ & 4.41 & 0.01 & $0.20 \%$ & $-0.09 \%$ & $0.29 \%$ & 0.001 & \begin{tabular}{|c|}
-0.003 \\
\end{tabular} & 0.004 \\
\hline$\gamma=2 \%$ & 4.12 & $7.64 \%$ & 4.25 & $7.72 \%$ & 4.24 & 0.00 & $0.10 \%$ & $-0.08 \%$ & $0.18 \%$ & $8.13 \%$ & 4.25 & $8.26 \%$ & 4.24 & 0.01 & $0.18 \%$ & $-0.10 \%$ & $0.28 \%$ & 0.000 & \begin{tabular}{|l|}
-0.003 \\
\end{tabular} & 0.003 \\
\hline$\gamma=3 \%$ & 3.96 & $7.58 \%$ & 4.08 & $7.66 \%$ & 4.08 & 0.00 & $0.09 \%$ & $-0.09 \%$ & $0.18 \%$ & $8.06 \%$ & 4.09 & $8.18 \%$ & 4.08 & 0.01 & $0.17 \%$ & $-0.11 \%$ & $0.28 \%$ & 0.000 & \begin{tabular}{|c|}
-0.003 \\
\end{tabular} & 0.003 \\
\hline$\gamma=4 \%$ & 3.80 & $7.53 \%$ & 3.93 & $7.60 \%$ & 3.92 & 0.00 & $0.09 \%$ & $-0.09 \%$ & $0.18 \%$ & $7.99 \%$ & 3.93 & $8.11 \%$ & 3.92 & 0.01 & $0.14 \%$ & $-0.12 \%$ & $0.26 \%$ & -0.001 & \begin{tabular}{|l|l|}
-0.003 \\
\end{tabular} & 0.002 \\
\hline$\kappa=1 \%$ & 4.46 & $7.76 \%$ & 4.54 & $7.85 \%$ & 4.53 & 0.01 & $0.13 \%$ & $\begin{array}{c}-0.01 \% \\
\end{array}$ & $0.13 \%$ & $8.27 \%$ & 4.54 & $8.43 \%$ & 4.53 & 0.01 & $0.22 \%$ & $0.00 \%$ & $0.22 \%$ & \begin{tabular}{ll|}
0.001 \\
\end{tabular} & \begin{tabular}{|l|l|}
-0.003 \\
\end{tabular} & 0.004 \\
\hline$\kappa=2 \%$ & 4.46 & $7.73 \%$ & $\begin{array}{l}4.49 \\
\end{array}$ & $7.84 \%$ & 4.48 & 0.01 & $0.13 \%$ & $0.06 \%$ & $0.07 \%$ & $8.24 \%$ & $\begin{array}{l}4.49 \\
\end{array}$ & $8.41 \%$ & 4.48 & 0.01 & $0.22 \%$ & $0.08 \%$ & $0.13 \%$ & 0.001 & \begin{tabular}{|l|l|}
-0.003 \\
\end{tabular} & 0.004 \\
\hline$\kappa=3 \%$ & 4.46 & $7.72 \%$ & 4.44 & $7.81 \%$ & 4.43 & 0.01 & $0.12 \%$ & $0.12 \%$ & $0.00 \%$ & $8.22 \%$ & 4.44 & $8.38 \%$ & 4.43 & 0.01 & $0.20 \%$ & $0.16 \%$ & $0.04 \%$ & 0.001 & -0.003 & 0.004 \\
\hline$\kappa=4 \%$ & 4.46 & $7.70 \%$ & $\begin{array}{l}4.39 \\
\end{array}$ & $7.80 \%$ & $\begin{array}{l}4.38 \\
\end{array}$ & 0.01 & $0.12 \%$ & $0.18 \%$ & $-0.05 \%$ & $8.20 \%$ & 4.39 & $8.36 \%$ & 4.38 & 0.01 & $0.20 \%$ & $0.24 \%$ & $-0.03 \%$ & 0.001 & -0.003 & 0.004 \\
\hline$\delta=10 \%$ & 4.46 & $7.23 \%$ & 4.67 & $7.28 \%$ & 4.67 & 0.00 & $0.06 \%$ & $-0.17 \%$ & $0.23 \%$ & $7.62 \%$ & 4.70 & $7.70 \%$ & 4.69 & 0.00 & $0.10 \%$ & $-0.28 \%$ & $0.37 \%$ & \begin{tabular}{|l|}
-0.023 \\
\end{tabular} & \begin{tabular}{|c|}
-0.025 \\
\end{tabular} & 0.002 \\
\hline$\delta=30 \%$ & 4.46 & $7.59 \%$ & 4.62 & $7.67 \%$ & 4.61 & 0.00 & $0.10 \%$ & $\begin{array}{l}-0.12 \% \\
\end{array}$ & $0.22 \%$ & $8.07 \%$ & 4.63 & $8.20 \%$ & 4.62 & 0.01 & $0.17 \%$ & $\begin{array}{r}-0.17 \% \\
\end{array}$ & $0.33 \%$ & \begin{tabular}{|c|}
-0.008 \\
\end{tabular} & \begin{tabular}{|c|}
-0.011 \\
\end{tabular} & 0.003 \\
\hline$\delta=50 \%$ & 4.46 & $7.95 \%$ & 4.56 & $8.07 \%$ & 4.56 & 0.01 & $0.16 \%$ & $0.00 \%$ & $0.17 \%$ & $8.52 \%$ & 4.56 & $8.71 \%$ & 4.55 & 0.01 & $0.27 \%$ & $0.03 \%$ & $0.24 \%$ & 0.010 & 0.005 & 0.005 \\
\hline$\delta=70 \%$ & 4.46 & $8.31 \%$ & 4.51 & $8.48 \%$ & 4.50 & 0.01 & $0.23 \%$ & $0.17 \%$ & $0.06 \%$ & $8.97 \%$ & 4.49 & $9.26 \%$ & 4.47 & 0.02 & $0.42 \%$ & $0.34 \%$ & $0.07 \%$ & 0.031 & 0.023 & 0.008 \\
\hline$\tau=10 \%$ & 4.46 & $7.77 \%$ & 4.46 & $7.87 \%$ & 4.45 & 0.01 & $0.17 \%$ & $0.14 \%$ & $\begin{array}{l}0.03 \% \\
\end{array}$ & $8.28 \%$ & $\begin{array}{l}4.44 \\
\end{array}$ & $8.45 \%$ & 4.43 & 0.01 & $0.30 \%$ & $0.25 \%$ & $0.06 \%$ & $\begin{array}{l}0.024 \\
\end{array}$ & 0.018 & 0.006 \\
\hline$\tau=30 \%$ & $\begin{array}{l}4.46 \\
\end{array}$ & $7.77 \%$ & 4.73 & $7.87 \%$ & 4.73 & 0.00 & $0.10 \%$ & $\begin{array}{l}-0.27 \% \\
\end{array}$ & $0.37 \%$ & $8.30 \%$ & 4.76 & $8.46 \%$ & 4.75 & 0.01 & $0.14 \%$ & $\begin{array}{l}-0.41 \% \\
\end{array}$ & $0.55 \%$ & \begin{tabular}{|l|}
-0.024 \\
\end{tabular} & \begin{tabular}{|l|l|}
-0.026 \\
\end{tabular} & 0.002 \\
\hline$\tau=40 \%$ & 4.46 & $7.77 \%$ & 4.87 & $7.87 \%$ & 4.87 & 0.00 & $0.05 \%$ & $\begin{array}{l}-0.47 \% \\
\end{array}$ & $0.52 \%$ & $8.31 \%$ & 4.92 & $8.47 \%$ & 4.92 & 0.00 & $0.07 \%$ & $-0.74 \%$ & $0.81 \%$ & \begin{tabular}{|c|}
-0.050 \\
\end{tabular} & \begin{tabular}{|c|}
-0.051 \\
\end{tabular} & 0.001 \\
\hline$\tau=50 \%$ & 4.46 & $7.77 \%$ & 5.02 & $7.86 \%$ & 5.02 & 0.00 & $0.01 \%$ & $-0.63 \%$ & $0.65 \%$ & $8.32 \%$ & 5.10 & $8.48 \%$ & 5.10 & 0.00 & $0.00 \%$ & $-1.06 \%$ & $1.07 \%$ & \begin{tabular}{|c|}
-0.079 \\
\end{tabular} & \begin{tabular}{|c|}
-0.079 \\
\end{tabular} & 0.000 \\
\hline$r=2 \%$ & 3.80 & $4.45 \%$ & 3.78 & $4.59 \%$ & 3.77 & 0.01 & $0.21 \%$ & $0.17 \%$ & $0.03 \%$ & $4.85 \%$ & 3.78 & $5.05 \%$ & 3.76 & 0.01 & $0.31 \%$ & $0.24 \%$ & $0.07 \%$ & \begin{tabular}{c|}
0.010 \\
\end{tabular} & 0.006 & 0.004 \\
\hline$r=10 \%$ & 5.22 & $11.29 \%$ & 5.51 & $11.36 \%$ & \begin{tabular}{|l|}
5.50 \\
\end{tabular} & 0.00 & $0.08 \%$ & $-0.14 \%$ & $0.22 \%$ & $11.85 \%$ & 5.53 & $11.99 \%$ & 5.52 & 0.01 & $0.15 \%$ & $-0.25 \%$ & $0.40 \%$ & -0.018 & \begin{tabular}{|l|l|}
-0.023 \\
\end{tabular} & 0.004 \\
\hline$r=14 \%$ & 6.10 & $14.91 \%$ & 6.54 & $14.95 \%$ & $\begin{array}{ll}6.54 \\
\end{array}$ & 0.00 & $0.03 \%$ & $-0.19 \%$ & $0.23 \%$ & $15.46 \%$ & 6.59 & $15.55 \%$ & 6.59 & 0.01 & $0.09 \%$ & $-0.32 \%$ & $0.41 \%$ & \begin{tabular}{|c|}
-0.049 \\
\end{tabular} & \begin{tabular}{|l|}
-0.053 \\
\end{tabular} & 0.004 \\
\hline$r=18 \%$ & 7.03 & $18.62 \%$ & 7.63 & $18.64 \%$ & $\begin{array}{l}7.63 \\
\end{array}$ & 0.00 & $0.02 \%$ & $-0.15 \%$ & $0.17 \%$ & $19.11 \%$ & 7.72 & $19.17 \%$ & 7.72 & 0.00 & $0.05 \%$ & $-0.30 \%$ & $0.35 \%$ & \begin{tabular}{|l|}
-0.088 \\
\end{tabular} & \begin{tabular}{|c|}
-0.090 \\
\end{tabular} & 0.003 \\
\hline$T^{I}=0.5$ & 1.06 & $8.71 \%$ & 1.12 & $8.79 \%$ & 1.12 & 0.00 & \begin{tabular}{|l|l|}
$0.28 \%$ \\
\end{tabular} & $-0.20 \%$ & $0.41 \%$ & 9.57\% & 1.12 & \begin{tabular}{|l|l|}
$9.70 \%$ \\
\end{tabular} & 1.11 & 0.00 & $0.44 \%$ & $\begin{array}{l}-0.19 \% \\
\end{array}$ & $0.62 \%$ & 0.005 & 0.004 & 0.002 \\
\hline$T^{I}=1.5$ & 3.52 & $8.00 \%$ & 3.64 & $8.09 \%$ & 3.64 & 0.01 & $0.15 \%$ & $-0.08 \%$ & $0.22 \%$ & $8.60 \%$ & 3.64 & $8.76 \%$ & 3.63 & 0.01 & $0.26 \%$ & $-0.09 \%$ & $0.36 \%$ & 0.004 & \begin{tabular}{|c|}
-0.001 \\
\end{tabular} & 0.004 \\
\hline$T^{I}=2.5$ & $\begin{array}{l}5.25 \\
\end{array}$ & $7.58 \%$ & 5.40 & $\begin{array}{l}7.68 \% \\
\end{array}$ & 5.39 & 0.01 & $0.11 \%$ & $\begin{array}{l}-0.06 \% \\
\end{array}$ & $0.17 \%$ & $8.03 \%$ & 5.40 & $8.20 \%$ & 5.39 & 0.01 & $0.18 \%$ & $\begin{array}{l}-0.07 \% \\
\end{array}$ & $0.26 \%$ & \begin{tabular}{|l|}
-0.001 \\
\end{tabular} & $\begin{array}{l}-0.005 \\
\end{array}$ & 0.004 \\
\hline$T^{I}=3.5$ & $\begin{array}{l}6.54 \\
\end{array}$ & $7.27 \%$ & 6.70 & $7.38 \%$ & $\begin{array}{l}6.69 \\
\end{array}$ & 0.01 & $0.09 \%$ & $-0.05 \%$ & $0.15 \%$ & $7.62 \%$ & 6.71 & $7.79 \%$ & 6.70 & 0.01 & $0.16 \%$ & $-0.07 \%$ & $0.22 \%$ & -0.003 & \begin{tabular}{|l|l|}
-0.007 \\
\end{tabular} & 0.004 \\
\hline$T^{c}=6$ & 1.97 & $7.57 \%$ & 2.02 & $7.68 \%$ & 2.02 & 0.00 & $0.14 \%$ & $-0.05 \%$ & $0.19 \%$ & $7.95 \%$ & 2.02 & $8.13 \%$ & 2.02 & 0.00 & $0.22 \%$ & $-0.04 \%$ & $0.26 \%$ & 0.002 & 0.000 & 0.002 \\
\hline$T^{c}=10$ & 7.55 & $7.78 \%$ & 7.80 & $7.88 \%$ & \begin{tabular}{l|l|}
7.79 \\
\end{tabular} & 0.01 & $0.13 \%$ & $-0.08 \%$ & $0.21 \%$ & $8.36 \%$ & 7.81 & $8.51 \%$ & 7.80 & 0.02 & $0.22 \%$ & $-0.12 \%$ & $0.34 \%$ & -0.008 & \begin{tabular}{|l|l|}
-0.015 \\
\end{tabular} & 0.007 \\
\hline$T^{c}=14$ & 14.32 & $7.72 \%$ & $\begin{array}{l}14.86 \\
\end{array}$ & $7.80 \%$ & $\begin{array}{ll}14.84 \\
\end{array}$ & 0.02 & \begin{tabular}{|l|l|}
$0.11 \%$ \\
\end{tabular} & $-0.10 \%$ & $0.21 \%$ & $8.31 \%$ & \begin{tabular}{|l|}
14.93 \\
\end{tabular} & $8.44 \%$ & 14.90 & 0.03 & $0.19 \%$ & $\begin{array}{l}-0.17 \% \\
\end{array}$ & $0.36 \%$ & \begin{tabular}{|c|}
-0.059 \\
\end{tabular} & \begin{tabular}{|c|}
-0.071 \\
\end{tabular} & 0.012 \\
\hline$T^{c}=18$ & 20.77 & $7.65 \%$ & 21.61 & $7.71 \%$ & \begin{tabular}{|l|}
21.59 \\
\end{tabular} & 0.02 & $0.10 \%$ & $-0.11 \%$ & $0.21 \%$ & $8.21 \%$ & 21.77 & $8.32 \%$ & 21.73 & 0.03 & $0.15 \%$ & $-0.20 \%$ & $0.35 \%$ & -0.143 & \begin{tabular}{c|}
-0.155 \\
\end{tabular} & 0.012 \\
\hline
\end{tabular}


Table 5: Analysis of the impact of different market conditions and asset characteristics on the agency costs of debt and on the optimal debt levels. Once again, we have not reflected the impact of the changes of the parameters on $P$. Thereby, the results must be analysed in a similar way to Table 4 .

\begin{tabular}{|c|c|c|c|c|c|c|c|c|c|c|c|c|c|c|c|c|c|c|c|c|c|c|c|c|}
\hline \multirow{2}{*}{ Parameter } & \multirow{2}{*}{$V_{0}{ }^{U}$} & \multicolumn{10}{|c|}{ Constant debt amortization schedule $(\mathrm{CA})$} & \multicolumn{10}{|c|}{ Constant debt repayment schedule (CR) } & \multicolumn{3}{|c|}{ Relative advantage of CA over $\mathrm{CR}$} \\
\hline & & $F^{F}$ & $r_{d}{ }^{F}$ & $V_{0}^{F}$ & $F^{s}$ & $r_{d}{ }^{s}$ & $V_{0}^{s}$ & $A$ & $A \%$ & $A^{\Gamma} \%$ & $A^{\Omega} \%$ & $F^{F}$ & $r_{d}{ }^{F}$ & $V_{0}{ }^{F}$ & $F^{s}$ & $r_{d}{ }^{s}$ & $V_{0}^{S}$ & $A$ & $A \%$ & $A^{\Gamma} \%$ & $A^{\Omega} \%$ & $-V_{0}^{S(C R)}$ & $-V_{0}{ }^{F(C R)}$ & $A^{(C A)}-A^{(C)}$ \\
\hline Base Case & 4.458 & 23.75 & $7.609 \%$ & 4.591 & 22.25 & $7.476 \%$ & 4.587 & 004 & $0.088 \%$ & $-0.038 \%$ & $0.127 \%$ & 24.50 & $8.210 \%$ & 4.594 & 22.25 & $7.964 \%$ & 4.588 & 0.006 & $0.131 \%$ & $-0.061 \%$ & $0.192 \%$ & -0.001 & \begin{tabular}{|c|}
-0.003 \\
\end{tabular} & \\
\hline$\sigma=10 \%$ & 0.056 & 36.75 & $6.149 \%$ & 0.092 & 6.75 & $6.152 \%$ & 0.092 & 000 & $0.043 \%$ & $-0.953 \%$ & $996 \%$ & 33.00 & $6.204 \%$ & 0.089 & 33.00 & $6.207 \%$ & 0.089 & 0.000 & $.044 \%$ & $-0.932 \%$ & $0.977 \%$ & 0.003 & 0.003 & \\
\hline$\sigma=30 \%$ & 2.597 & 25.25 & $6.933 \%$ & 2.735 & 24.75 & $6.910 \%$ & 2.734 & .001 & $0.050 \%$ & $-0.116 \%$ & $0.167 \%$ & 23.25 & $7.121 \%$ & 2.730 & 22.50 & $7.058 \%$ & 2.728 & 0.002 & $0.056 \%$ & $-0.115 \%$ & $0.171 \%$ & 0.005 & 0.005 & . 000 \\
\hline$\sigma=50 \%$ & 6.404 & 30.50 & $9.010 \%$ & 6.553 & 23.50 & $8.329 \%$ & 6.535 & 0018 & $0.273 \%$ & $0.075 \%$ & $0.198 \%$ & 37.00 & $10.214 \%$ & 6.588 & 24.25 & $8.940 \%$ & 6.546 & 0.042 & $0.649 \%$ & $0.331 \%$ & $0.318 \%$ & -0.011 & \begin{tabular}{|c|}
-0.035 \\
\end{tabular} & \\
\hline$\sigma=70 \%$ & 10.145 & 9.75 & $9.211 \%$ & 10.497 & 6.00 & $8.863 \%$ & $\begin{array}{l}10.309 \\
\end{array}$ & & $1.824 \%$ & $1.353 \%$ & $471 \%$ & 49.75 & $9.197 \%$ & 10.580 & 25.75 & $9.078 \%$ & 10.328 & 0.252 & $2.436 \%$ & $1.706 \%$ & $0.730 \%$ & -0.019 & \begin{tabular}{|c|}
-0.082 \\
\end{tabular} & \\
\hline$\alpha=3 \%$ & 528 & 49.75 & $6.888 \%$ & 0.604 & 31.50 & $6.931 \%$ & 0.577 & 027 & $4.754 \%$ & $2.733 \%$ & $1.237 \%$ & 49.75 & $6.910 \%$ & 0.610 & 30.75 & $7.001 \%$ & 0.580 & 0.030 & $5.113 \%$ & $3.228 \%$ & $1.884 \%$ & -0.003 & \begin{tabular}{|c|}
-0.006 \\
\end{tabular} & .002 \\
\hline$\alpha=5 \%$ & 2.88 & 25.25 & $7.656 \%$ & 2.981 & 23.25 & $7.503 \%$ & 2.977 & .004 & $0.143 \%$ & $-0.054 \%$ & $0.197 \%$ & 27.25 & $8.345 \%$ & 2.987 & 23.25 & $7.938 \%$ & 2.979 & 0.008 & $0.253 \%$ & $-0.047 \%$ & $0.300 \%$ & -0.002 & \begin{tabular}{|c|}
-0.006 \\
\end{tabular} & 003 \\
\hline$\alpha=7 \%$ & 6.171 & 24.00 & $7.693 \%$ & 6.339 & 3.00 & $7.619 \%$ & $\begin{array}{l}6.335 \\
\end{array}$ & 004 & $0.066 \%$ & $-0.048 \%$ & $0.114 \%$ & 23.50 & $8.164 \%$ & 6.339 & 22.25 & $8.049 \%$ & 6.333 & 0.006 & $.093 \%$ & $-0.061 \%$ & $0.154 \%$ & 0.001 & 0.000 & \\
\hline$\alpha=9 \%$ & 9.73 & 23.75 & $7.712 \%$ & 9.975 & 22.50 & $7.592 \%$ & 9.970 & 005 & $0.050 \%$ & \begin{tabular}{|l|}
$-0.036 \%$ \\
\end{tabular} & $0.086 \%$ & 22.75 & $8.158 \%$ & 9.972 & 21.25 & $7.968 \%$ & \begin{tabular}{l|l}
9.966 \\
\end{tabular} & 0.006 & $0.064 \%$ & $-0.040 \%$ & $0.104 \%$ & 0.005 & 0.003 & 0.0 \\
\hline$\gamma=1 \%$ & 4.285 & 25.00 & $7.704 \%$ & 4.416 & 23.50 & $7.580 \%$ & $\begin{array}{ll}4.413 \\
\end{array}$ & .004 & $\begin{array}{l}0.086 \% \\
\end{array}$ & \begin{tabular}{|c|}
$-0.064 \%$ \\
\end{tabular} & $0.150 \%$ & 25.25 & $8.248 \%$ & \begin{tabular}{|l|l|}
4.419 \\
\end{tabular} & 22.50 & $\begin{array}{l}7.927 \% \\
\end{array}$ & 4.413 & 0.006 & $0.136 \%$ & \begin{tabular}{|c|}
$-0.060 \%$ \\
\end{tabular} & $0.196 \%$ & -0.001 & \begin{tabular}{|c|}
-0.003 \\
\end{tabular} & 0.002 \\
\hline$\gamma=2 \%$ & 4.11 & 25.25 & $7.675 \%$ & 4.247 & 24.25 & $7.617 \%$ & 4.244 & 004 & $0.087 \%$ & \begin{tabular}{|c|}
$-0.073 \%$ \\
\end{tabular} & $0.160 \%$ & 25.25 & $8.170 \%$ & 4.250 & 23.25 & $7.972 \%$ & 4.244 & 0.006 & $0.137 \%$ & $-0.072 \%$ & $0.209 \%$ & -0.001 & \begin{tabular}{|c|}
-0.003 \\
\end{tabular} & .002 \\
\hline$\gamma=3 \%$ & 931 & 26.00 & $7.708 \%$ & 4.084 & 4.25 & $7.558 \%$ & 4.080 & 004 & $0.088 \%$ & $-0.072 \%$ & $0.160 \%$ & 26.25 & $8.243 \%$ & 4.087 & 24.00 & $8.019 \%$ & 4.081 & 0.006 & $0.146 \%$ & $-0.087 \%$ & $0.232 \%$ & -0.001 & \begin{tabular}{|c|}
-0.003 \\
\end{tabular} & \\
\hline$\gamma=4 \%$ & 3.8 & 26.25 & $7.680 \%$ & 3.926 & 24.50 & $7.534 \%$ & 3.923 & 004 & $0.092 \%$ & $-0.074 \%$ & $0.166 \%$ & 26.75 & $8.241 \%$ & $\begin{array}{l}3.930 \\
\end{array}$ & 24.25 & $\begin{array}{l}7.989 \% \\
\end{array}$ & 3.924 & 0.006 & $0.154 \%$ & \begin{tabular}{|c|}
$-0.088 \%$ \\
\end{tabular} & $0.241 \%$ & -0.001 & \begin{tabular}{|c|}
-0.003 \\
\end{tabular} & 0.002 \\
\hline$\kappa=1 \%$ & 4.458 & 21.00 & $7.263 \%$ & 4.545 & 19.75 & $7.152 \%$ & $\begin{array}{l}4.543 \\
\end{array}$ & 002 & $\begin{array}{l}0.038 \% \\
\end{array}$ & \begin{tabular}{|l|l|}
$-0.020 \%$ \\
\end{tabular} & $0.057 \%$ & 20.75 & $7.640 \%$ & \begin{tabular}{|l|}
4.548 \\
\end{tabular} & \begin{tabular}{ll|}
19.50 \\
\end{tabular} & $7.518 \%$ & \begin{tabular}{l|l}
4.545 \\
\end{tabular} & \begin{tabular}{|c|}
0.003 \\
\end{tabular} & $0.056 \%$ & \begin{tabular}{|c|}
$-0.030 \%$ \\
\end{tabular} & $0.086 \%$ & -0.002 & \begin{tabular}{|c|}
-0.003 \\
\end{tabular} & 0.001 \\
\hline$\kappa=2 \%$ & 4.458| & 16.75 & $6.806 \%$ & 4.506 & 16.00 & $6.747 \%$ & \begin{tabular}{l|l}
4.505 \\
\end{tabular} & .000 & $0.010 \%$ & \begin{tabular}{|c|}
$-0.005 \%$ \\
\end{tabular} & $0.015 \%$ & 16.50 & $7.076 \%$ & 4.509 & 16.25 & $7.068 \%$ & 4.508 & 0.001 & $0.018 \%$ & $-0.012 \%$ & $0.030 \%$ & -0.003 & -0.004 & \\
\hline$\kappa=3 \%$ & 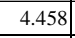 & 11.75 & $6.388 \%$ & 4.476 & 11.75 & $6.390 \%$ & 476 & 000 & $02 \%$ & $-0.001 \%$ & $0.003 \%$ & 11.75 & $6.560 \%$ & 4.480 & 11.75 & $6.565 \%$ & 4.480 & 0.000 & $0.004 \%$ & \begin{tabular}{|c|}
$-0.002 \%$ \\
\end{tabular} & $0.006 \%$ & -0.004 & \begin{tabular}{|l|}
-0.004 \\
\end{tabular} & \\
\hline$\kappa=4 \%$ & 458 & 4.00 & $6.029 \%$ & 4.459 & 4.00 & $6.029 \%$ & 4.459 & 0.000 & $0.000 \%$ & $0.000 \%$ & $0.000 \%$ & 5.75 & $6.121 \%$ & \begin{tabular}{l|l}
4.462 \\
\end{tabular} & 5.75 & $6.121 \%$ & \begin{tabular}{l|l}
4.462 \\
\end{tabular} & 0.000 & $0.000 \%$ & $0.000 \%$ & $0.000 \%$ & -0.003 & \begin{tabular}{|c|}
-0.003 \\
\end{tabular} & 0.000 \\
\hline$\delta=10 \%$ & 458 & 49.75 & $10.790 \%$ & 4.829 & 36.25 & $8.892 \%$ & 4.731 & .098 & (779\% & $0.607 \%$ & $1.473 \%$ & 49.75 & $11.558 \%$ & 4.932 & 37.00 & $9.873 \%$ & 4.767 & 0.165 & $3.467 \%$ & $0.890 \%$ & $2.577 \%$ & -0.036 & \begin{tabular}{|c|}
-0.103 \\
\end{tabular} & 0.067 \\
\hline$\delta=30$ & \begin{tabular}{|l|l|}
4.458 \\
\end{tabular} & 30.00 & 8.2 & 4.625 & 26.75 & 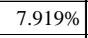 & 15 & 10 & $3 \%$ & $69 \%$ & $0.283 \%$ & 32.25 & $9.198 \%$ & 4.641 & 75 & $6 \%$ & 4.623 & 0.018 & $0.396 \%$ & $-0.044 \%$ & $0.439 \%$ & -0.008 & \begin{tabular}{|l|l|}
-0.016 \\
\end{tabular} & \\
\hline$\delta=50 \%$ & $\begin{array}{l}4.458 \\
\end{array}$ & 20.50 & $7.344 \%$ & 4.572 & 20.25 & $7.353 \%$ & 4.570 & 0.002 & $\begin{array}{l}0.043 \% \\
\end{array}$ & $-0.037 \%$ & $0.080 \%$ & 19.75 & $7.671 \%$ & $\begin{array}{l}4.569 \\
\end{array}$ & 19.00 & \begin{tabular}{|l|l|}
$7.614 \%$ \\
\end{tabular} & 4.567 & 0.003 & $0.057 \%$ & \begin{tabular}{|c|}
$-0.042 \%$ \\
\end{tabular} & $0.099 \%$ & 0.003 & $\begin{array}{ll}0.002 \\
\end{array}$ & 0.001 \\
\hline$\delta=70 \%$ & 4.458 & 16.25 & $7.023 \%$ & 4.549 & 6.25 & $7.042 \%$ & 4.548 & 001 & $0.016 \%$ & $-0.018 \%$ & $0.034 \%$ & 14.75 & $7.173 \%$ & 4.544 & 14.75 & $7.198 \%$ & 4.543 & 0.001 & $0.017 \%$ & $-0.020 \%$ & $0.037 \%$ & 0.005 & 0.005 & 00 \\
\hline$\tau=10 \%$ & 4.458] & 13.75 & $6.550 \%$ & 4.497 & 13.75 & 6.556\% & \begin{tabular}{|l|l|}
4.497 \\
\end{tabular} & 0.000 & $0.005 \%$ & $-0.004 \%$ & $0.009 \%$ & 12.25 & $6.619 \%$ & \begin{tabular}{|l|l|}
4.494 \\
\end{tabular} & 12.25 & $6.625 \%$ & 4.494 & 0.000 & $0.006 \%$ & \begin{tabular}{|c|}
$-0.004 \%$ \\
\end{tabular} & $0.009 \%$ & 0.003 & $\begin{array}{l}0.003 \\
\end{array}$ & 000 \\
\hline$\tau=30 \%$ & & 35.50 & $9.402 \%$ & 4.773 & 31.00 & $8.937 \%$ & $\begin{array}{l}.747 \\
\end{array}$ & 226 & $0.557 \%$ & $-0.248 \%$ & $0.805 \%$ & 41.50 & $11.344 \%$ & 4.842 & 31.75 & $9.958 \%$ & $\begin{array}{l}.779 \\
\end{array}$ & 0.063 & $1.318 \%$ & \begin{tabular}{|c|}
$-0.080 \%$ \\
\end{tabular} & $1.397 \%$ & -0.032 & \begin{tabular}{|l|l|}
-0.069 \\
\end{tabular} & 0.031 \\
\hline$\tau=40 \%$ & 4.458 & 46.00 & $11.537 \%$ & 081 & 36.75 & $10.385 \%$ & 989 & 2 & $551 \%$ & \begin{tabular}{|l|l|}
$-0.685 \%$ \\
\end{tabular} & $2.535 \%$ & 49.75 & $13.275 \%$ & 5.325 & 39.00 & $12.408 \%$ & 5.10 & 0.219 & $4.294 \%$ & $-1.253 \%$ & $5.547 \%$ & -0.116 & \begin{tabular}{|l|}
-0.243 \\
\end{tabular} & 0.127 \\
\hline$\tau=50 \%$ & 4.458 & 49.75 & \begin{tabular}{|l|l|}
$12.498 \%$ \\
\end{tabular} & 5.528 & 41.75 & $12.304 \%$ & 5.330 & 0.198 & $3.706 \%$ & $-2.641 \%$ & $6.347 \%$ & 49.75 & $13.517 \%$ & 5.927 & 43.50 & $14.983 \%$ & 5.602 & 0.325 & $5.809 \%$ & $-8.044 \%$ & $13.852 \%$ & -0.272 & -0.400 & 0.128 \\
\hline$r=2 \%$ & 3.802 & 11.25 & $2.607 \%$ & 222 & 10.50 & $2.534 \%$ & 224 & 0 & \begin{tabular}{|c|}
$0.003 \%$ \\
\end{tabular} & $0.000 \%$ & $0.003 \%$ & 10.50 & $2.619 \%$ & 3.821 & 10.00 & $2.566 \%$ & 3.8 & 0.000 & 0.003\% & \begin{tabular}{|c|}
$-0.001 \%$ \\
\end{tabular} & $.003 \%$ & 0.001 & 0.6 & 0.000 \\
\hline$r=10 \%$ & & 31.25 & $076 \%$ & 27 & 29.00 & $11.927 \%$ & 14 & & $244 \%$ & $-0.139 \%$ & $0.384 \%$ & 33.25 & $13.087 \%$ & 5.557 & 28.25 & $12.547 \%$ & 5.5 & 027 & $0.482 \%$ & $-0.119 \%$ & $.600 \%$ & -0.017 & -0.0 & \\
\hline$r=14 \%$ & $\begin{array}{l}6.097 \\
\end{array}$ & 36.00 & \begin{tabular}{|l|l|}
$16.231 \%$ \\
\end{tabular} & 6.616 & 32.75 & $15.969 \%$ & 592 & 0.024 & $0.361 \%$ & $-0.295 \%$ & $0.656 \%$ & 38.75 & $17.405 \%$ & 6.696 & 32.25 & $16.734 \%$ & 6.642 & 0.054 & $0.809 \%$ & $-0.281 \%$ & $1.090 \%$ & -0.050 & \begin{tabular}{|c|}
-0.080 \\
\end{tabular} & \\
\hline$r=18 \%$ & 7.035 & 39.75 & $20.256 \%$ & 7.799 & 36.00 & $19.986 \%$ & 7.761 & 0.038 & $0.496 \%$ & $-0.401 \%$ & $0.897 \%$ & 42.50 & $21.394 \%$ & $\begin{array}{l}7.946 \\
\end{array}$ & 36.00 & $20.883 \%$ & 7.859 & 0.087 & $1.106 \%$ & $-0.483 \%$ & $1.589 \%$ & -0.098 & \begin{tabular}{|l|l|}
-0.146 \\
\end{tabular} & 0.048 \\
\hline$T^{I}=0.5$ & & 19. & $7.622 \%$ & 126 & 8.25 & $7.473 \%$ & 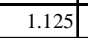 & 31 & $0.081 \%$ & $-0.147 \%$ & $0.228 \%$ & 18.50 & $8.042 \%$ & 1.126 & 18.25 & $8.019 \%$ & 1.1 & 0.001 & $0.057 \%$ & $-0.210 \%$ & $0.267 \%$ & & & \\
\hline$T^{I}=1.5$ & 3.52. & 22.75 & $7.670 \%$ & 3.644 & 21.50 & $7.541 \%$ & 3.641 & 0.003 & $0.071 \%$ & $-0.065 \%$ & $0.136 \%$ & 22.50 & $8.159 \%$ & 3.645 & 21.00 & $7.977 \%$ & 3.641 & 0.004 & $0.105 \%$ & $-0.087 \%$ & $0.192 \%$ & 0.000 & \begin{tabular}{|c|}
-0.001 \\
\end{tabular} & 0.001 \\
\hline$T^{I}=2.5$ & $\begin{array}{l}5.253 \\
\end{array}$ & 26.00 & $7.702 \%$ & 5.395 & 23.75 & $7.516 \%$ & 5.389 & 0.006 & $0.107 \%$ & $-0.032 \%$ & $0.139 \%$ & 27.00 & $8.316 \%$ & 5.400 & 23.25 & $\begin{array}{l}7.914 \% \\
\end{array}$ & 5.391 & 0.009 & $0.169 \%$ & \begin{tabular}{|c|}
$-0.025 \%$ \\
\end{tabular} & 0.194\% & $\begin{array}{l}-0.002 \\
\end{array}$ & \begin{tabular}{|l|}
-0.005 \\
\end{tabular} & 0.003 \\
\hline$T^{I}=3.5$ & & 30.25 & $.787 \%$ & 6.703 & 5.50 & $7.432 \%$ & $\begin{array}{ll}6.692 \\
\end{array}$ & 1 & $0.166 \%$ & $0.023 \%$ & $143 \%$ & 32.25 & $410 \%$ & 6.714 & 25.75 & $7.887 \%$ & 6.695 & .019 & $0.286 \%$ & $0.061 \%$ & $.225 \%$ & -0.003 & .011 & 0.008 \\
\hline$T^{c}=6$ & 1.96 & 23.50 & $7.378 \%$ & 2.024 & 22.00 & $7.250 \%$ & 2.022 & 0. & $0.069 \%$ & $-0.045 \%$ & $0.114 \%$ & 23.25 & $7.698 \%$ & 2.024 & 21.50 & $7.532 \%$ & 2.022 & 0.002 & $0.101 \%$ & \begin{tabular}{|c|}
$-0.051 \%$ \\
\end{tabular} & $0.152 \%$ & 0.001 & 0.000 & 0. \\
\hline$T^{c}=10$ & 7.55 & 26.25 & $7.943 \%$ & 7.799 & 24.50 & $7.808 \%$ & 7.790 & 0.010 & $0.124 \%$ & $-0.061 \%$ & $0.185 \%$ & 27.00 & $8.656 \%$ & \begin{tabular}{ll|}
7.816 \\
\end{tabular} & 24.25 & $8.378 \%$ & \begin{tabular}{l|l|}
7.799 \\
\end{tabular} & 0.017 & $0.222 \%$ & \begin{tabular}{|c|}
$-0.064 \%$ \\
\end{tabular} & $0.286 \%$ & -0.009 & \begin{tabular}{|c|}
-0.017 \\
\end{tabular} & 0.008 \\
\hline$T^{c}=14$ & 4.324 & 30.75 & $8.343 \%$ & 14.881 & 27.50 & $8.099 \%$ & 14.846 & 0.034 & $0.230 \%$ & $-0.056 \%$ & $0.286 \%$ & 33.50 & $9.389 \%$ & 4.984 & 28.25 & $8.909 \%$ & 4.912 & 0.073 & $0.487 \%$ & $-0.044 \%$ & $0.531 \%$ & -0.0 & 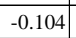 & \\
\hline$T^{c}=18$ & 20.772 & 34.00 & $8.505 \%$ & 21.703 & 30.25 & $8.272 \%$ & 21.631 & 0.071 & $0.329 \%$ & $-0.047 \%$ & $0.376 \%$ & 39.25 & $9.757 \%$ & 21.969 & 31.25 & $9.105 \%$ & 21.804 & 0.165 & $0.758 \%$ & $0.012 \%$ & $0.746 \%$ & -0.172 & \begin{tabular}{c|}
-0.266 \\
\end{tabular} & \\
\hline
\end{tabular}




\section{Graphs}

Graph 1: Principal balances on the two repayment schedules considered during the life of the loans. The values reflect optimal debt levels and fair interest rates considering the investment option secondbest exercise policy. The parameters are the ones defined for the base case and the optimal amounts of debt are 22.25 for both cases with an interest rate of $7.48 \%$ for the constant amortization schedule and $7.96 \%$ for the constant repayment schedule.

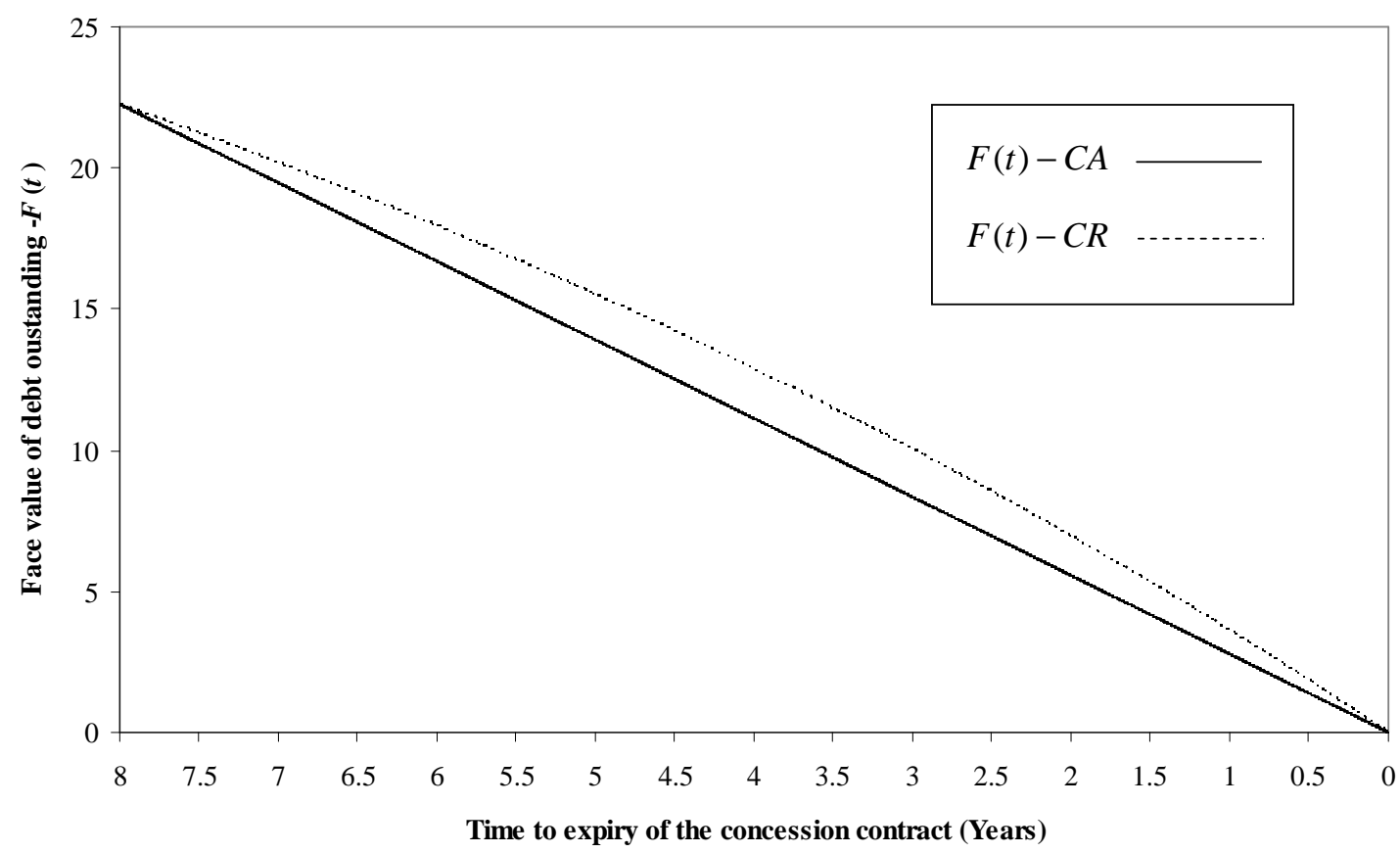

Graph 2 Default boundaries for the two repayment schedules during the life of the loans / concession contract. Again, the values reflect optimal debt levels and fair interest rates considering the investment option second-best exercise policy. The parameters are the ones defined for the base case and the optimal amounts of debt are 22.25 for both cases with an interest rate of $7.48 \%$ for the constant amortization schedule and $7.96 \%$ for the constant repayment schedule.

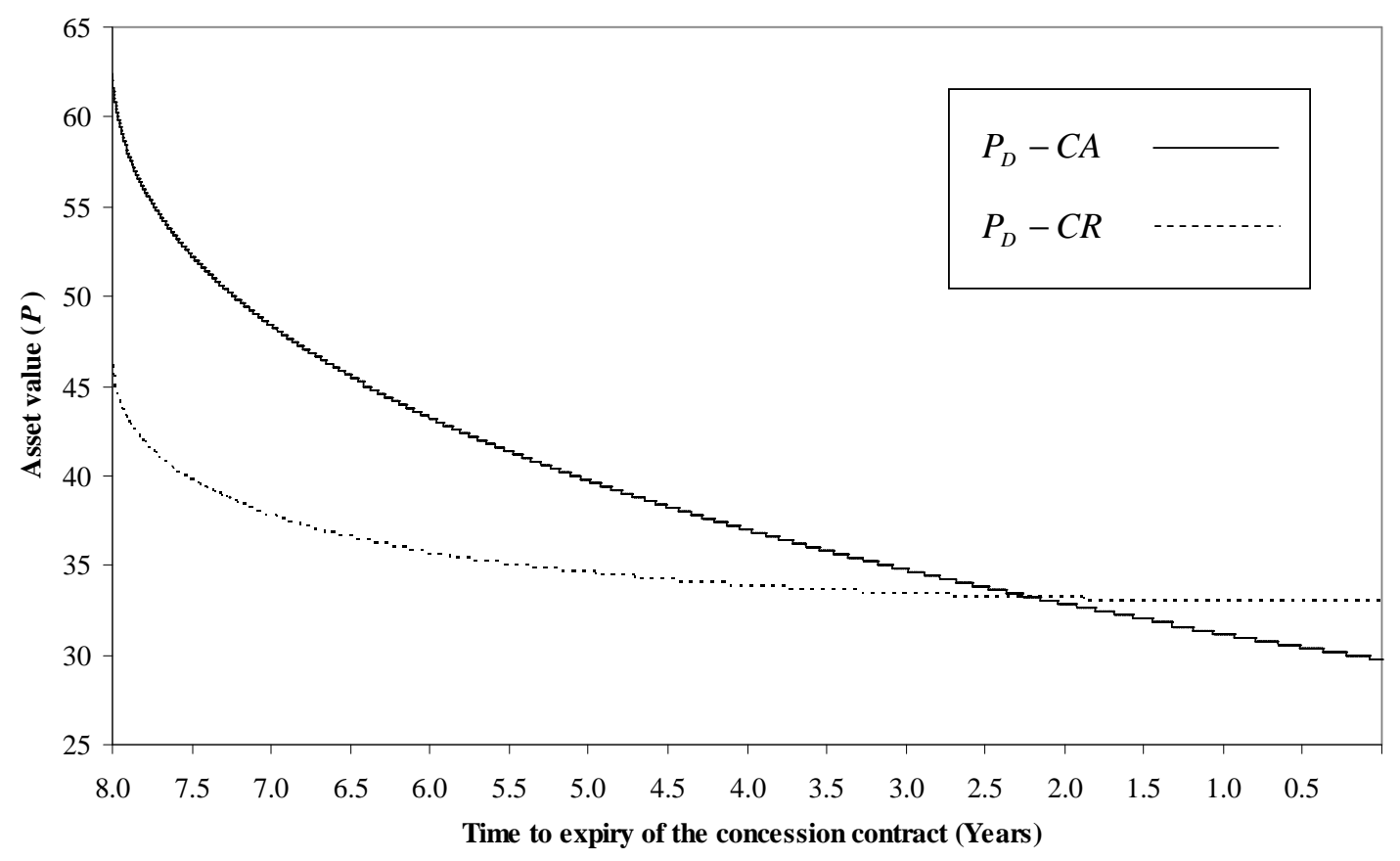


Graph 3: Investment exercise boundaries during the life of the option to invest for the unlevered and levered first-best and second-best policies.

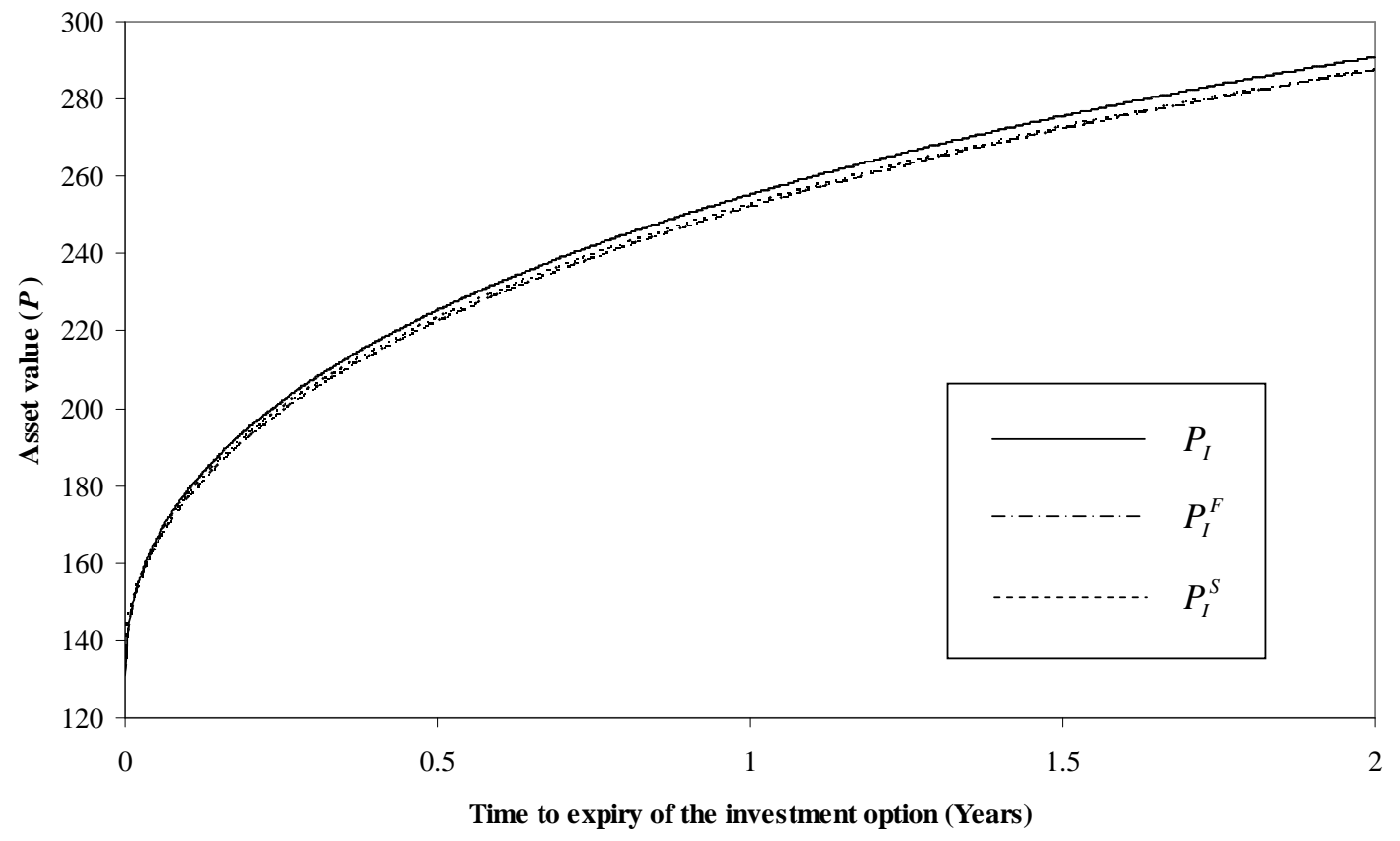

Graph 4: Analysis of the decision to invest at the expiry moment of the investment option for the constant amortization schedule. The parameters are the ones defined in the base case, the optimal amount of debt and the fair interest rate, were determined assuming a first-best policy.

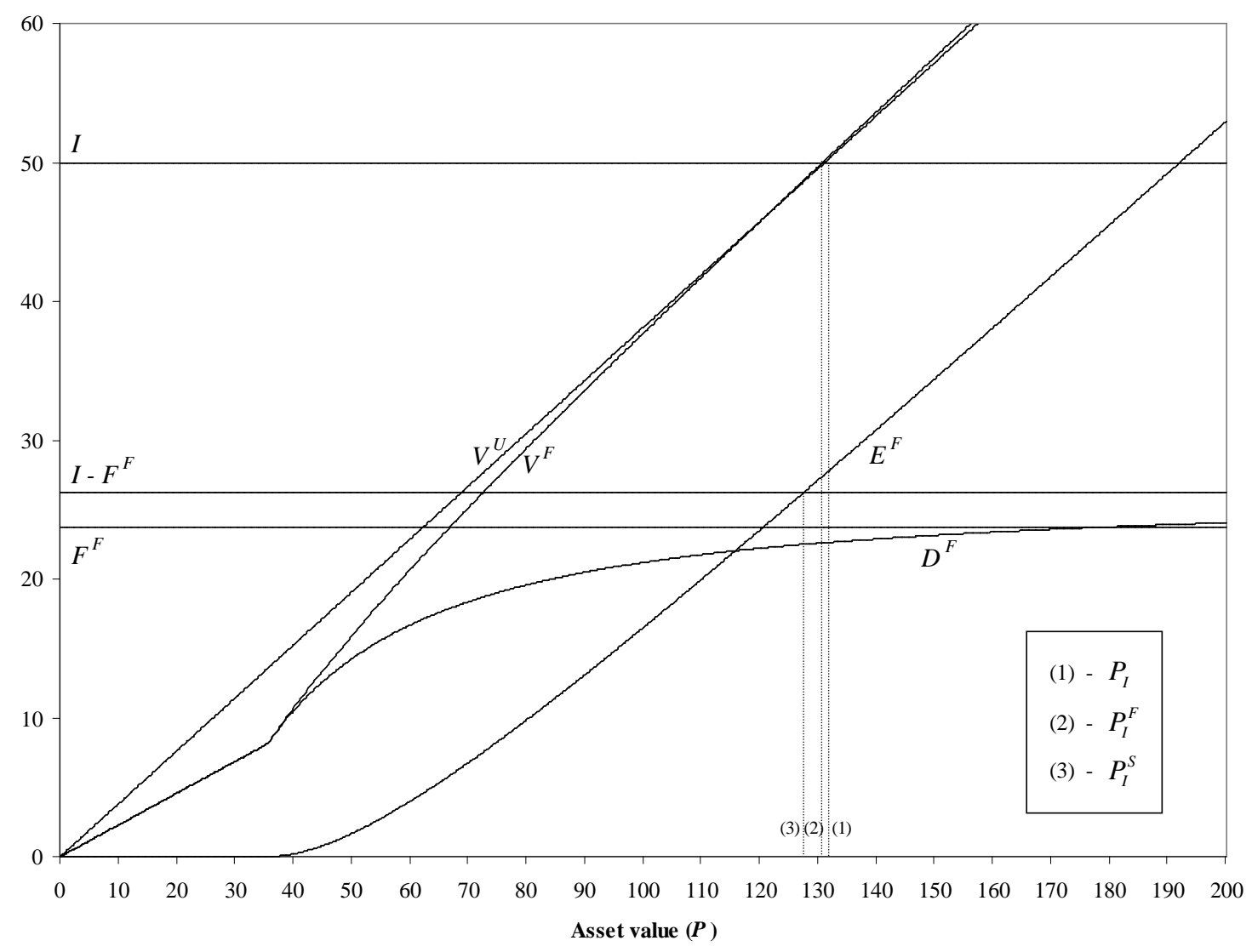

